\title{
Transfer of electrons on scratched iron surfaces: Photoelectron emission and X-ray photoelectron spectroscopy studies
}

\author{
Yoshihiro MOMOSE ${ }^{1,{ }^{*}}$, Daisuke SUZUKI ${ }^{1}$, Keika TSURUYA ${ }^{1}$, Takao SAKURAI ${ }^{2}$, Keiji NAKAYAMA $^{3}$ \\ ${ }^{1}$ Department of Materials Science, Ibaraki University, 4-12-1 Nakanarusawa, Hitachi 316-8511, Japan \\ ${ }^{2}$ Ashikaga Institute of Technology, Ashikaga 326-8558, Japan \\ ${ }^{3}$ Institute of Mesotechnology, 2-2-1-201 Nakahara, Kashiwa 277-0085, Japan \\ Received: 22 March 2017 / Revised: 27 April 2017 / Accepted: 22 May 2017 \\ C The author(s) 2017. This article is published with open access at Springerlink.com
}

\begin{abstract}
We report the activation energy, $\Delta E_{a}$ for the quantum yield in thermally assisted photoelectron emission (TAPE) under 210-nm-wavelength light irradiation, and the associated X-ray photoelectron spectroscopy (XPS) results. Samples were cleaned only in acetone and scratched in air, water, methanol, ethanol, acetone, benzene, and cyclohexane. Glow curves, describing the temperature dependence of photoelectron emission (PE) quantum yield (emitted electrons/photon), $Y$, were obtained. A simple method of determining $\Delta E_{\mathrm{a}}$ using $Y$, called $Y_{\mathrm{GC}}$ at seven temperatures up to $353{ }^{\circ} \mathrm{C}$, for the same $Y$ glow curve, was proposed. The $\Delta E_{\mathrm{a}}$ obtained using this method was almost the same as that obtained from $Y$ for seven stationary temperatures $\left(Y_{\mathrm{ST}}\right)$. For scratched samples, the TAPE was measured over two cycles of temperature increase and subsequent decrease (Up1, Down1 and Up2, Down2 scans) in the $25-339{ }^{\circ} \mathrm{C}$ range, and $\Delta E_{\mathrm{a}}$ was obtained from $Y_{\mathrm{GC}}$. The Arrhenius plot was approximated by a straight line, although a convex swelling peak appeared in the Up1 scan. $\Delta E_{\mathrm{aUp} 1}$ was in the $0.212-0.035 \mathrm{eV}$ range, depending on the environment in which scratching was performed; $\Delta E_{\mathrm{aUp}}$ for water was much higher than that for acetone. This was explained in terms of the mode of the acid-base interaction between the liquid molecules and the hydroxyl group of Fe-OH. The values of $\Delta E_{\mathrm{aDown} 1}, \Delta E_{\mathrm{aUp} 2}$ and $\Delta E_{\mathrm{aDown} 2}$ were in the $0.038-0.012 \mathrm{eV}$ range. The total count of electrons emitted during the Up1 and Up2 scans was found to decrease with increasing $\Delta E_{\mathrm{aUp} 1}$ and $\Delta E_{\mathrm{aUp} 2}$, respectively. $\Delta E_{\mathrm{aUp} 2}$ was found to increase with increasing presence of the FeO component in the analyzed Fe oxides. The convex swelling peak was attributed to the removal of carbon materials from the scratched surface and the effect of the increased electron density of the surface hydroxyl group of $\mathrm{FeOH}$ under the light irradiation.
\end{abstract}

Keywords: thermally assisted photoelectron emission; XPS; real iron; scratch-inducing environment; Arrhenius activation energy; environment molecule-surface hydroxyl group interaction

\section{Introduction}

Much attention has been given to studying the role of charge transfer and electronic excitation in the overlayers of real metallic surfaces in various problems in tribology, adhesion, and corrosion. However, little is known about the behavior of electrons in these superficial layers, owing to the difficulties associated with experimental measurements of such electrons.
Photoelectron emission (PE) occurs when photons are absorbed by electrons, leading to the release of these photon-absorbing electrons from the surface. For real iron surfaces, however, little electron emission is observed at temperatures close to room temperature, even in response to irradiation by photons with the energy higher than the metal's work function. This is caused by the effect of the surface overlayer. The surface overlayer consists of adsorbed species such as

* Corresponding author: Yoshihiro MOMOSE, E-mail: y.momose@cpost.plala.or.jp 
oxides, hydroxyl groups, carbon materials, and reaction products, owing to the metal's interaction with its environment. To understand the trapping or transport of electrons excited from the metal base on the surface overlayer, we have studied the temperature dependence of PE from real iron surfaces, using a non-vacuum-based method. The theoretical basis of PE is well-captured by the Spicer's three-step model [1], which prescribes that the emission process occurs in three successive steps: (a) optical excitation, (b) transport of the excited electrons to the surface, and (c) release of the excited electrons into vacuum. We previously obtained the activation energies of quantum yields and electron PE probabilities, for PE from real iron surfaces cleaned only in acetone. These quantum yields and probabilities were obtained for different temperatures and wavelengths, using the PE analysis of Fowler [2] and DuBridge [3, 4] and XPS analysis $[5,6]$. The observed reduction in the PE intensity at low temperatures was attributed to the ability of the surface overlayer to transmit the incident light, which is the rate-limiting step in the PE process. Therefore, we believe that the surface overlayer assumes two roles in PE: (a) controlling the penetration or absorption of the incident light and (b) controlling the transfer of excited metallic electrons to the overlayer and their subsequent transport to the outermost surface.

We have also previously reported PE and XPS results for scratched real iron surfaces [7], which we briefly summarize here. The metal surfaces were scratched using a diamond cutter, in seven environments: air, water, methanol, ethanol, acetone, benzene, and cyclohexane. The PE intensity was then measured as a function of temperature in response to the $210 \mathrm{~nm}$ wavelength irradiation, using a Geiger counter. Temperature sweeps (in the $25-339^{\circ} \mathrm{C}$ range) were performed in two cycles of temperature increase and subsequent reduction. The first cycle consisted of Up1 and Down1 scans, while the second cycle consisted of Up2 and Down2 scans. PE glow curves (PE intensity vs. temperature) were obtained, with four glow curves for each scratched sample, as shown in Fig. 1 in Ref. [7]. The PE glow curves that were obtained in the Up1 scans were found to be strongly affected by the environment in which scratching was performed, while those that were obtained in the other scans exhibited a similar behavior and were almost environment-independent. The Up1 scan PE glow curves for temperatures in the $40-339^{\circ} \mathrm{C}$ range, and the XPS results that were obtained at 25, 200, and $339{ }^{\circ} \mathrm{C}$, revealed the following: (a) The PE intensity gradually increased with temperature, with a broad convex swelling peak in the $150-250^{\circ} \mathrm{C}$ range, depending on the environment. (b) At $40{ }^{\circ} \mathrm{C}$, the PE intensities in the different environments satisfied: air $<$ water $\approx$ methanol $\approx$ cyclohexane $<$ ethanol $<$ benzene $<$ acetone. (c) For all environments except acetone and benzene, the PE intensity in the Up1 scan significantly increased with increasing the presence of two oxygen components, $\mathrm{OH}^{-}$and $\mathrm{O}^{2-}$, in the overlayer, $\mathrm{Zo}=\mathrm{O}^{2} /\left(\mathrm{OH}^{-}+\mathrm{O}^{2-}\right)$, up to $200{ }^{\circ} \mathrm{C}$. Above that temperature, the PE intensity increased more gently until $339^{\circ} \mathrm{C}$. (d) The Arrhenius plot of the Zo values for samples scratched in methanol and cyclohexane yielded a straight line, corresponding to the $\Delta$ Ezo activation energies of $0.023 \mathrm{eV}$ (methanol) and $0.043 \mathrm{eV}$ (cyclohexane). These values were much lower than the value of $0.113 \mathrm{eV}$ that was obtained for real iron surfaces cleaned only in acetone [6]. These $\Delta E$ zo values will be compared with the $\Delta E_{\text {a }}$ values obtained in the present study. (e) The PE intensity increased with the decreasing presence of $\mathrm{Fe}$ as one of Fe components in the overlayer, for all environments except benzene in the $200-339{ }^{\circ} \mathrm{C}$ range. (f) With the increasing $\mathrm{FeOOH}$ content, the PE intensity increased in the $25-200{ }^{\circ} \mathrm{C}$ range, but in the $200-339{ }^{\circ} \mathrm{C}$ range the PE intensity for air, water, methanol, ethanol, and cyclohexane environments increased with almost the same content of $\mathrm{FeOOH}$, while for acetone and benzene environments the PE intensity remained almost constant.

The goals of the present study were: (a) to establish a simple method of estimating $\Delta E_{\mathrm{a}}$ from the PE glow curve; (b) to determine $\Delta E_{\mathrm{a}}$ during the increase in the PE quantum yield with increasing temperature, for all temperature scans; (c) to clarify the relationship between $\Delta E_{\mathrm{a}}$ and the total count of emitted electrons in the Up1 scan, for different environments; (d) to clarify the relationship between $\Delta E_{\mathrm{a}}$ in the Up1 scan and the acid-base interaction of the environment's liquid molecules with surface hydroxyl groups $(\mathrm{Fe}-\mathrm{OH})$ and with the $\Delta E_{\mathrm{ZO}}$ of $Z_{\mathrm{O}}$; (e) to clarify the relationship 
between the total count of emitted electrons in the Up2 scan and both $\Delta E_{\mathrm{a}}$ and the intensity of iron oxide in the Fe3p XPS spectra; (f) to determine the mechanism of convex swelling in the PE glow curves.

\section{Experimental}

\subsection{Materials}

The metal samples were $99.5 \%$ purity 0.1 -mm-thick commercial rolled iron sheets (Nilaco, Tokyo, Japan). The samples' dimensions were $20 \mathrm{~mm} \times 30 \mathrm{~mm}$. Prior to use, the samples were ultrasonically cleaned in $30 \mathrm{~mL}$ acetone (reagent grade) for $15 \mathrm{~min}$ twice (i.e., total cleaning time of $30 \mathrm{~min}$ ), dried in vacuum for $15 \mathrm{~min}$, and then kept in a desiccator. An as-cleaned sample, i.e., only cleaned in acetone, was used as a reference for $\Delta E_{\mathrm{a}}$ values obtained from both $Y_{\mathrm{ST}}$ and $Y_{\mathrm{GC}}$. The cleaned samples were scratched as follows. The sample to be scratched was placed in ambient air, distilled water, or an organic liquid (reagent grade) in a glass Petri dish, and the entire surface of the sample was then scratched uniformly using a manually operated diamond cutter; the scratching was performed at room temperature and lasted $5 \mathrm{~min}$. The organic liquids used were methanol $\left(\mathrm{CH}_{3} \mathrm{OH}\right)$, ethanol $\left(\mathrm{C}_{2} \mathrm{H}_{5} \mathrm{OH}\right)$, acetone $\left(\left(\mathrm{CH}_{3}\right)_{2} \mathrm{CO}\right)$, benzene $\left(\mathrm{C}_{6} \mathrm{H}_{6}\right)$, and cyclohexane $\left(\mathrm{C}_{6} \mathrm{H}_{12}\right)$. Finally, the scratched surfaces were dried in vacuum for $15 \mathrm{~min}$. In addition to measuring the PE glow curves for the scratched surfaces, we also measured the PE glow curve for the unscratched sample.

\subsection{Thermally assisted PE and XPS}

Figure 1 schematically shows the experimental setup for measuring TAPE [5]. The system consisted of an electron measuring chamber filled with a flowing $Q$ gas, an electron counting system, a light irradiation system, and a heating system. The measuring chamber was basically a gas-flow type Geiger-Müller counter, consisting of an earthed cylindrical brass cathode (diameter, $40 \mathrm{~mm}$ ) with a brass grid (mesh gauze, 30), and a tungsten wire ring anode (wire diameter, $100 \mu \mathrm{m})$. A stainless sample holder with a heater and a chromel-alumel thermocouple was connected to a temperature controller (Rigaku, Akishima, Tokyo). The sample holder was vertically installed $20 \mathrm{~mm}$ below the grid. A quartz glass window was inserted into the side wall of the apparatus for light irradiation. The light irradiation system consisted of a grating monochromator and a wavelength drive unit connected to a UV light source. The light source was a deuterium lamp (Hamamatsu Photonics). In all experiments, the direction of the light irradiation was approximately normal to the plane of the analyzed sample. The sample's area exposed to the incident light was $0.5 \mathrm{~mm} \times 3 \mathrm{~mm}$. In the electron counting the voltage of $1,400 \mathrm{~V}$ was applied to the anode. The electron counting process can be explained as follows. First,

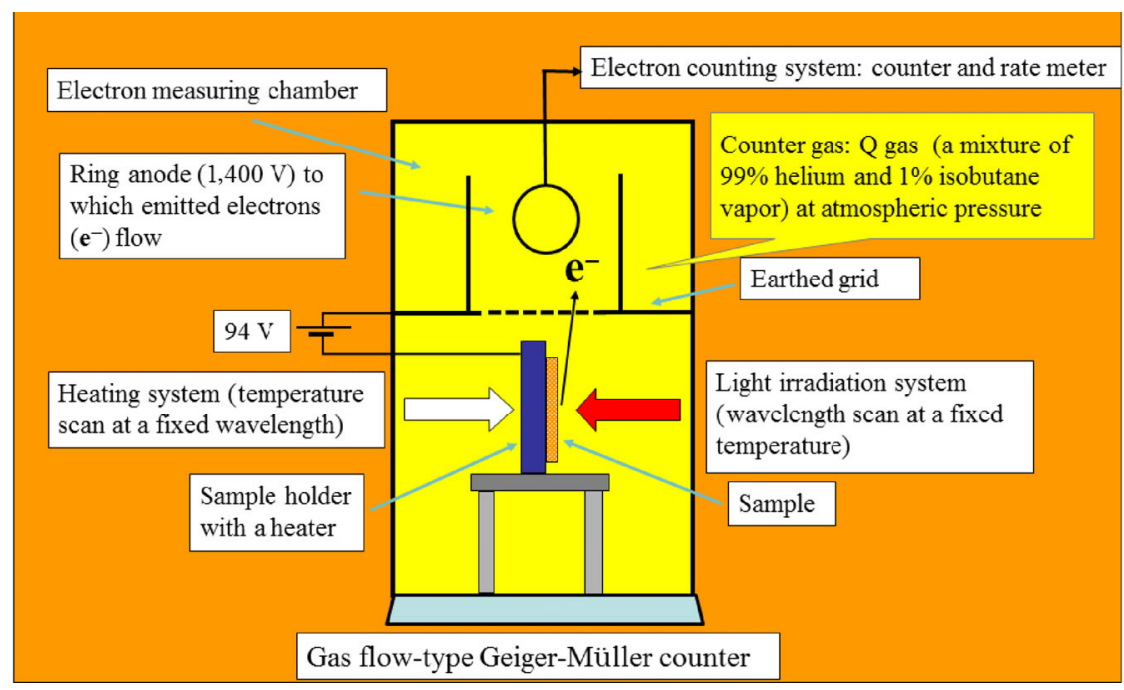

Fig. 1 Experimental setup for measuring thermally assisted PE from real surfaces. 
the electrons that are released from the sample surface in response to light irradiation are attracted toward the earthed grid, because the sample is negatively biased relative to the grid. Next, the electrons pass through the grid and reach the anode. Finally, gas multiplication by the $\mathrm{Q}$ gas yields more electrons, resulting in the production of a measurable pulse. Thus, the number of the emitted electrons can be counted by a radiation counter and a linear count rate meter.

In the TAPE measurement, as shown in Fig. 1, the intensity of TAPE can be measured in two ways: (1) during a temperature scan under light irradiation at a fixed wavelength and (2) during a wavelength scan at a fixed temperature. This study reports the results for temperature scans at fixed wavelengths. After a sample had been mounted on the sample holder, the Q gas was allowed to continuously flow into the measuring chamber at a flow rate of $100 \mathrm{sccm}$ at atmospheric pressure, with the sample's surface directly exposed to the $Q$ gas. After that, the anode voltage was applied from the radiation counter (Ohyo koken Kogyo, Tokyo) and the sample was negatively biased at $94 \mathrm{~V}$ relative to the earthed grid, using a battery. The wavelengths of the incident light of interest in the present experiment, $\lambda$, were 200 and $210 \mathrm{~nm}$. The power of the light was measured using a power meter. For the samples cleaned only in acetone that were used to obtain $Y_{\mathrm{ST}}$ and $Y_{\mathrm{GC}}$, two light wavelengths were used: $200 \mathrm{~nm}$ (photon energy $=6.199 \mathrm{eV}$, light intensity $=1.07 \times 10^{11}$ photons $\left./ \mathrm{s}\right)$ and $210 \mathrm{~nm}(5.904 \mathrm{eV}$, $1.28 \times 10^{11}$ photons $\left./ \mathrm{s}\right)$. For the scratched and unscratched samples that were used to obtain only $Y_{\mathrm{GC}}$, only the $210 \mathrm{~nm}\left(1.16 \times 10^{11}\right.$ photons/s $)$ irradiation was used.

Below, we describe the procedure of TAPE measurements in the temperature scans at fixed wavelengths. The measurements were conducted as follows: (a) for the samples cleaned only in acetone the glow curves were measured up to seven maximal temperatures of $T_{\max }=25,108,152,203,254,303$, and $353^{\circ} \mathrm{C}$. Then, the analyzed samples were maintained at the maximal temperature for $\sim 5 \mathrm{~min}$. The heating rate in the glow curves measurements was $20^{\circ} \mathrm{C} / \mathrm{min}$. The maximal temperatures were chosen by taking into consideration the fact that desorption and chemical reactions on metal surfaces are well observed in the temperature range that includes these chosen values and the operational temperature of the Geiger-Müller counter; (b) for both the scratched and unscratched samples the glow curves were measured during the first cycle of temperature increase from 25 to $339^{\circ} \mathrm{C}$ (Up1 scan, required time: $950 \mathrm{~s}$ ) and subsequent decrease from 339 to $40{ }^{\circ} \mathrm{C}$ (Down1, 1,525 s), and then during a second cycle of increase from 40 to $339^{\circ} \mathrm{C}(\mathrm{Up} 2,900 \mathrm{~s})$ and subsequent decrease from 339 to $25^{\circ} \mathrm{C}$ (Down2, 1,548 s). The heating rate in the Up1 and Up2 scans was $20{ }^{\circ} \mathrm{C} / \mathrm{min}$, and the cooling rate in the Down1 and Down2 scans was $20^{\circ} \mathrm{C} / \mathrm{min}$ from 339 to $100{ }^{\circ} \mathrm{C}$, after which the samples were spontaneously cooled to room temperature. The second cycle scans were performed to examine the effect of the previous heating to $339{ }^{\circ} \mathrm{C}$ on the glow curves, because the surface overlayer is considered to attain a thermally stabilized structure after the first cycle of heating.

The results of the standard XPS measurements were previously reported in detail only for samples cleaned in acetone [5] and scratched in the different environments [7]. Here, we briefly describe the XPS analysis of the scratched samples. XPS was performed at $25^{\circ} \mathrm{C}$ after the PE wavelength scan from $300 \mathrm{~nm}$ to $200 \mathrm{~nm}$ at $25^{\circ} \mathrm{C}$, and after cooling to $25^{\circ} \mathrm{C}$ following the wavelength scans from $300 \mathrm{~nm}$ to $200 \mathrm{~nm}$ at $200{ }^{\circ} \mathrm{C}$ and $339^{\circ} \mathrm{C}$ [7]. The XPS measurements were conducted once for each experimental condition. Fe2p, O1s, $\mathrm{C} 1 \mathrm{~s}$, and Fe3p core spectra were measured using a Shimadzu ESCA 750 spectrometer (Shimadzu, Kyoto, Japan) with an $\mathrm{Mg} \mathrm{K} \alpha \mathrm{X}$-ray source ( $8 \mathrm{kV}$ and $30 \mathrm{~mA}$ ). The energy range and sensitivity factors were the same as described previously [5], except that the energy for Fe3p ranged from $65 \mathrm{eV}$ to $45 \mathrm{eV}$. The $\mathrm{O} 1 \mathrm{~s}$ spectra were resolved by curve-fitting using the Gaussian function, into two main components that were attributed to the hydroxyl $\left(\mathrm{OH}^{-}\right)$and oxide $\left(\mathrm{O}^{2-}\right)$ groups. The Fe3p and $\mathrm{Fe} 2 \mathrm{p}$ spectra were resolved into four components of $\mathrm{FeOOH}, \mathrm{Fe}_{2} \mathrm{O}_{3}\left(\mathrm{Fe}^{3+}\right)$, $\mathrm{FeO}\left(\mathrm{Fe}^{2+}\right)$, and Fe metal using the Gaussian and Lorentzian functions and the peak shape analysis method of Hesse et al. [8]. From the temperature dependence of the Fe3p and Fe2p spectra, the resolution of the Fe3p spectra was found to be better than that of the Fe2p spectra [7]. Therefore, the intensities of the four components in the Fe3p spectra were used in the following analysis. It is noted that the main peak in the $\mathrm{C} 1 \mathrm{~s}$ spectra appeared at the binding energy of $285 \mathrm{eV}$. 


\section{Results}

\subsection{Method to determine the activation energy from the PE quantum yield glow curve}

Conventionally, the PE quantum yield (emitted electrons/photon), $Y$, called $Y_{\mathrm{ST}}$, is obtained from the PE intensity measured when the final temperature $(T)$ of the PE glow curve is held stationary, and then the logarithm of $Y_{\mathrm{ST}}$ is plotted against $1 / T$ ( $T$ in kelvin) to obtain $\Delta E_{\mathrm{a}}$ [5]. However, this method becomes time-consuming when many glow curves need to be measured. In contrast, in the simple method proposed here, the PE intensities are obtained by acquiring only one glow curve up to a maximal temperature, and then by setting the values of $Y$, called $Y_{\mathrm{GC}}$, at selected temperatures $(T) . \Delta E_{\mathrm{a}}$ is subsequently obtained by plotting the logarithm of $Y_{\mathrm{GC}}$ against $1 / T$. It is shown below that the $\Delta E_{\mathrm{a}}$ values obtained by the conventional and simple methods are in a good agreement, and therefore our simple method can be used to obtain $\Delta E_{\mathrm{a}}$.

Figure 2 shows electron emission intensities measured under irradiation by light with the wavelengths

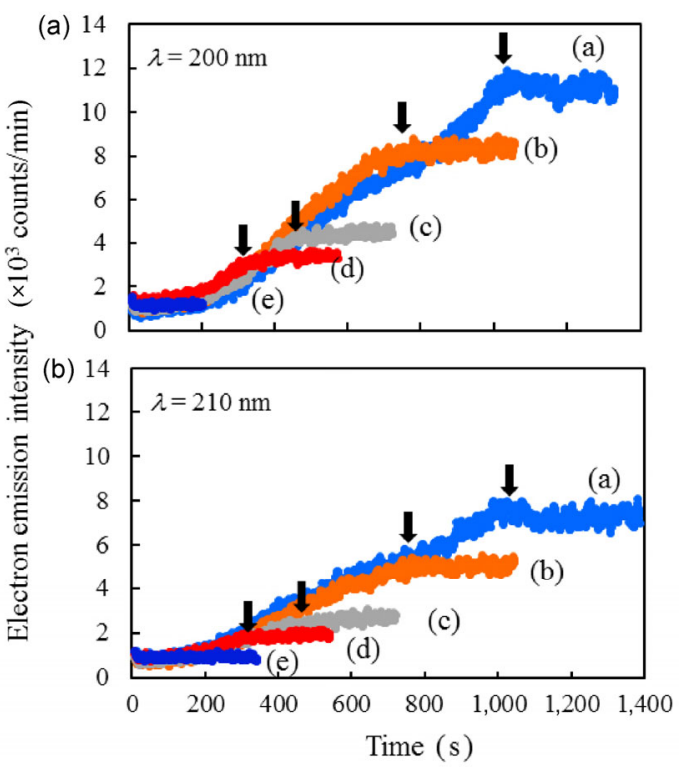

Fig. 2 Electron emission intensity vs. time during temperature scanning under light irradiation, for irradiations with $\lambda=200 \mathrm{~nm}$ (a) and $\lambda=210 \mathrm{~nm}$ (b). Samples cleaned only in acetone without scratching were used. The samples were heated to the final temperature $T_{\max }$ at a constant heating rate and then maintained at this temperature. The arrow on each curve denotes the time required to reach $T_{\max }$, which were (a) 353 , (b) 254 , (c) 152 , and (d) $108{ }^{\circ} \mathrm{C}$, and the curve for (e) $25^{\circ} \mathrm{C}$ was for no heating. of $200 \mathrm{~nm}$ and $210 \mathrm{~nm}$, as a function of time during temperature scanning, for a sample cleaned only in acetone. The emission intensity gradually increased with time and then saturated above the different times denoted by arrows that correspond to different $T_{\max }$. Both curves (a) to $T_{\max }=353{ }^{\circ} \mathrm{C}$ shown in Figs. 2(a) and 2 (b) also clearly exhibited a broad small convex swelling at $\sim 600 \mathrm{~s}$. The saturated emission intensity increased with $T_{\max }$ and became constant at $T_{\max }$. The saturated emission intensity was much higher at $200 \mathrm{~nm}$ than at $210 \mathrm{~nm} . T_{\max }$ was a stationary temperature, so the PE quantum yield in this case was denoted by $Y_{\mathrm{ST}}$ The Arrhenius-type equation for the sets of $Y_{\mathrm{ST}}$ and $T_{\max }$ under the irradiation by light with a given $\lambda$ is

$$
Y_{\mathrm{ST}}=Y_{\mathrm{o}} \exp \left(-\Delta E_{\mathrm{a}} / k_{\mathrm{B}} T\right)
$$

where $Y_{0}$ is the pre-exponential factor, $\Delta E_{\mathrm{a}}$ is the activation energy, $k_{\mathrm{B}}$ is Boltzmann's constant, and $T$ is the temperature of $T_{\max }$ in kelvins. Figure 3 shows Arrhenius plots of $\ln \left(Y_{\mathrm{ST}}\right)$ against the reciprocal of $T_{\max }$ for both $\lambda$. The $Y_{\text {ST }}$ values were determined from the saturated emission intensity and the incident photon intensity (units: photons/s), in the units of the number of emitted electrons per photon, using emitted electrons instead of counts for the saturated emission intensity. The Arrhenius plots were nearly linear over the entire range of temperatures, from $25^{\circ} \mathrm{C}$ to $353^{\circ} \mathrm{C}$,

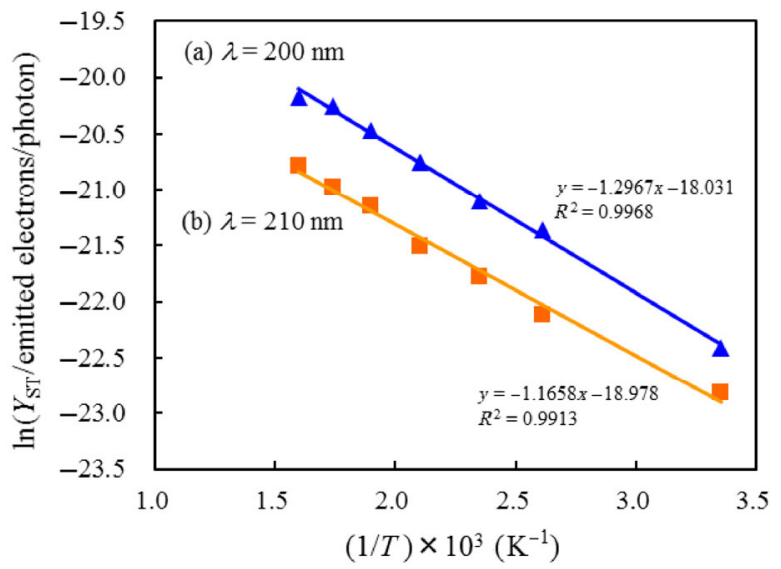

Fig. 3 Plots of $\ln \left(\mathrm{PE}\right.$ quantum yield, $\left.Y_{\mathrm{ST}}\right)$ at the final temperature, $T_{\max }$, vs. the reciprocal of the temperature in kelvins under light irradiation with $\lambda=200 \mathrm{~nm}$ (a) and $210 \mathrm{~nm}$ (b). Samples cleaned only in acetone without scratching were used. The $Y_{\mathrm{ST}}$ values were determined from the saturated electron emission intensity at $T_{\max }$ shown in Fig. 2 and the photon intensity at each $\lambda$. The equations and $R^{2}$ of the fitted straight lines are given in the figure. 
for both $\lambda$, indicating that the PE quantum yield, $Y_{\mathrm{ST}}$, obeyed the Arrhenius-type equation. The $\Delta E_{\mathrm{a}}$ and $Y_{\mathrm{o}}$ values obtained from $Y_{\text {ST }}$ are listed in Table 1 (Table 1 in Ref. [5]).

We next describe the proposed simple method for determining the activation energy. Figure 4 shows the curves of the PE quantum yield, $Y$, as a function of temperature during temperature scanning to $353^{\circ} \mathrm{C}$, for the irradiation light wavelengths of $200 \mathrm{~nm}$ and $210 \mathrm{~nm}$. These $Y$ glow curves correspond to the curves (a) in Figs. 2(a) and 2(b). The Arrhenius plots for the set of $Y_{\mathrm{GC}}$ values obtained at 40,100,150,200, 250, 300, and $339^{\circ} \mathrm{C}$, selected from the $Y$ glow curves at $200 \mathrm{~nm}$ and $210 \mathrm{~nm}$, are shown in Fig. 5. The data points clearly fall on a straight line for both wavelengths. In Table 1, the activation energy and the pre-exponential factor, $\Delta E_{\mathrm{a}}$ and $Y_{0}$, respectively, obtained from $Y_{\mathrm{ST}}$ and $Y_{\mathrm{GC}}$ are listed. The $\Delta E_{\mathrm{a}}$ values obtained from $Y_{\mathrm{GC}}$ were $14 \%$ at $200 \mathrm{~nm}$ and $6 \%$ at $210 \mathrm{~nm}$, higher than those that were obtained from $Y_{\mathrm{ST}}$, and the $Y_{0}$ values obtained from $Y_{\mathrm{GC}}$ were also somewhat higher than those obtained from $Y_{\mathrm{ST}}$, for both wavelengths. Considering the deviation of the $\Delta E_{\mathrm{a}}$ values at $210 \mathrm{~nm}$, we believe that $Y_{\mathrm{GC}}$ can be used for determining the value of $\Delta E_{\mathrm{a}}$ for the PE quantum yield. In addition, it is interesting that the light wavelength affects $Y_{\mathrm{GC}}$; the $\Delta E_{\mathrm{a}}$ values were higher for the wavelength of $200 \mathrm{~nm}$ than for the wavelength of $210 \mathrm{~nm}$, in the same way as those

Table 1 Comparison of Arrhenius activation energies $\left(\Delta E_{\mathrm{a}}\right)$ and pre-exponential factors $\left(Y_{0}\right)$ obtained from the two types of thermally assisted PE quantum yield, $Y_{\mathrm{ST}}$ and $Y_{\mathrm{GC}}$, under light irradiation with $\lambda=200$ and $210 \mathrm{~nm}^{\mathrm{a}}$.

\begin{tabular}{cccccc}
\hline $\begin{array}{c}\text { Type of the } \\
\text { quantum yield }\end{array}$ & $\begin{array}{c}\text { Wavelength } \\
(\lambda / \mathrm{nm})\end{array}$ & $\begin{array}{c}\text { Photon energy } \\
(h v / \mathrm{eV})\end{array}$ & $\begin{array}{c}\text { Light intensity } \\
\left(I_{h v} / 10^{11} \text { photons } / \mathrm{s}\right)\end{array}$ & $\begin{array}{c}\text { Activation energy } \\
\left(\Delta E_{\mathrm{a}} / \mathrm{eV}\right)\end{array}$ & $\begin{array}{c}\text { Pre-exponential factor } \\
\left(Y_{0} / 10^{-8} \text { emitted }\right. \\
\text { electrons/photon })\end{array}$ \\
\hline$Y_{\mathrm{ST}}$ & 200 & 6.199 & 1.07 & 0.112 & 1.47 \\
$Y_{\mathrm{GC}}$ & 200 & 6.199 & 1.07 & 0.128 & 0.100 \\
$Y_{\mathrm{ST}}$ & 210 & 5.904 & 1.28 & 0.106 & 0.57 \\
$Y_{\mathrm{GC}}$ & 210 & 5.904 & 1.28 & 0.69 \\
\hline
\end{tabular}

${ }^{\text {a) }} Y_{\mathrm{ST}}$ and $Y_{\mathrm{GC}}$ mean the quantum yields at stationary temperatures and at temperatures selected in one glow curve up to $353^{\circ} \mathrm{C}$, respectively.

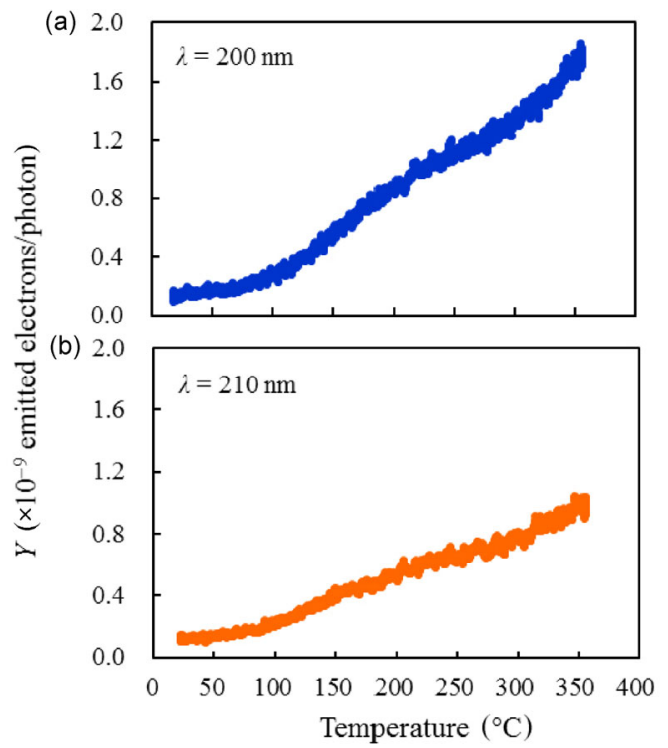

Fig. 4 PE quantum yield, $Y$, as a function of temperature during the temperature scan to $353{ }^{\circ} \mathrm{C}$, at a constant heating rate under light irradiation with $\lambda=200 \mathrm{~nm}$ (a) and $210 \mathrm{~nm}$ (b). Samples cleaned only in acetone without scratching were used.

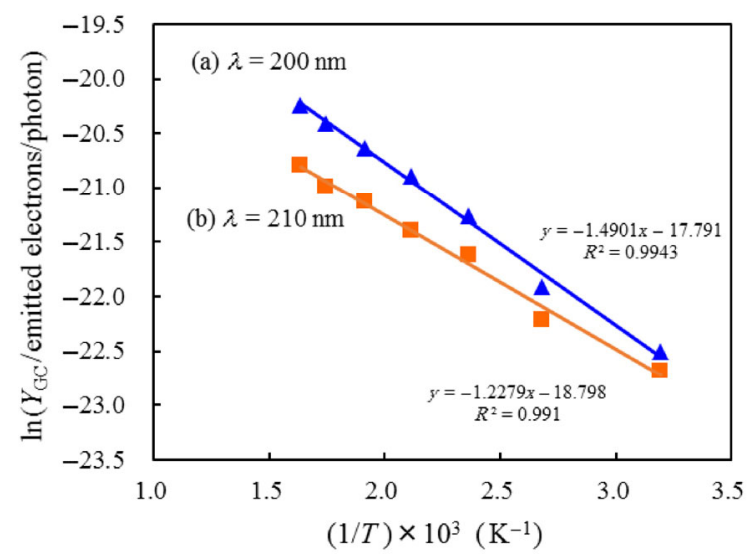

Fig. 5 Arrhenius plots of $\ln \left(\mathrm{PE}\right.$ quantum yield, $\left.Y_{\mathrm{GC}}\right)$ at selected temperatures in the glow curves for samples cleaned only in acetone without scratching. The $Y_{\mathrm{GC}}$ values were determined from the electron emission intensities at 40,100,150, 200, 250, 300, and $339^{\circ} \mathrm{C}$ in the glow curves shown in Fig. 4 and the photon intensity at $\lambda=200 \mathrm{~nm}$ (a) and $210 \mathrm{~nm}$ (b). The equations and $R^{2}$ of the fitted straight lines are given in the figure. 
obtained from $Y_{\mathrm{ST}}$ [5], although the reason for this remains unclear.

\subsection{Determination of activation energy for scratched real iron surfaces}

Figure 6 shows typical PE quantum yield glow curves obtained for the irradiation wavelength of $210 \mathrm{~nm}$, for a sample scratched in air. In the figure, the quantum yield, $Y$, in units of emitted electrons/photon is shown vs. the scan temperature, for the Up1, Down1, Up2, and Down2 scans. The glow curves for the Up 1 and Up2 scans, and those for the Down1 and Down2 scans, are shown together in the $40-339{ }^{\circ} \mathrm{C}$ range. The PE intensity glow curves for all scans of samples scratched in all environments and unscratched samples have been reported previously [7], in units of counts/min. Figures 7(a) to 7(h) show Arrhenius plots for the data obtained from $Y_{\mathrm{GC}}$ at seven selected temperatures in the Up1 and Up2 scans, for all scratched and unscratched samples. In these plots, $\ln \left(Y_{\mathrm{GC}}\right)$ is plotted against $1 / T$ on the same scale. In the case of the Up1 scan for environments such as water, methanol, and cyclohexane, the data points considerably deviated from a straight line owing to the broad convex swelling peak, while

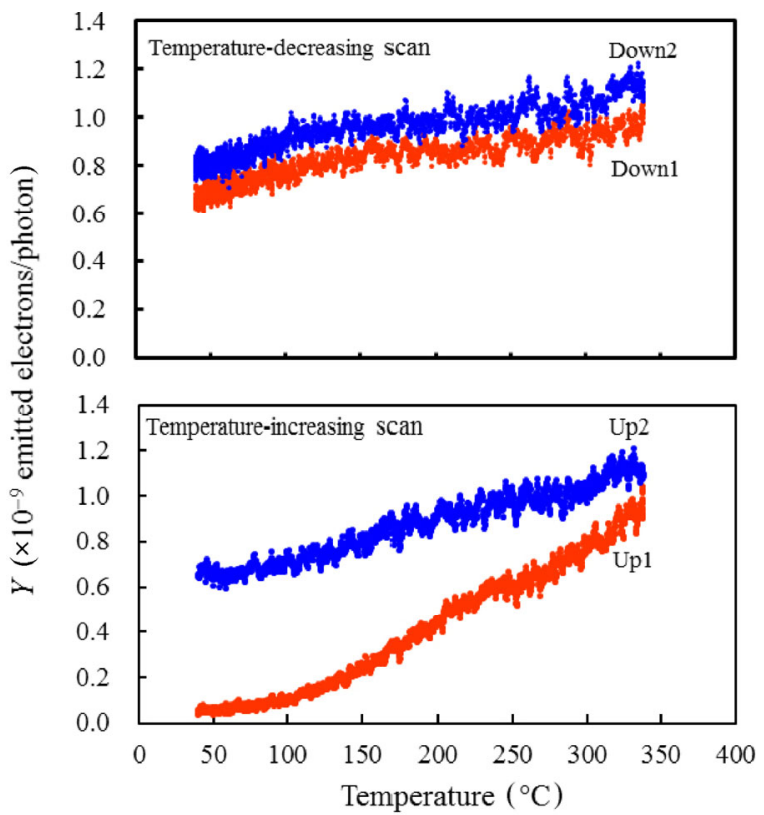

Fig. 6 Examples of the PE quantum yield, $Y$, as a function of temperature, for a sample scratched in air. The temperature successively increased and decreased in two cycles (Up1 and Down1, and Up2 and Down2 scans) in the $25-339^{\circ} \mathrm{C}$ range, under light irradiation with $\lambda=210 \mathrm{~nm}$. in the case of the Up2 scans, the data points fell on a straight line. We note that in the present study, a straight line approximation was needed as a first step toward examining the primary dependence of $\ln \left(Y_{\mathrm{GC}}\right)$ on temperature. Therefore, as shown in Fig. 7, the data obtained in all scans were approximated by a straight line, and the values of $\Delta E_{\mathrm{a}}$ and $Y_{0}$ were obtained from the slope and the intercept of the straight line, respectively. The broad convex swelling appearing in some of the PE glow curves is addressed later.

Table 2 summarizes the $\Delta E_{\mathrm{a}}$ values obtained from the Up1, Down1, Up2, and Down2 scans and the $Y_{0}$ values obtained from the Up1 scan, for the scratched and unscratched samples. The activation energies for the oxygen component ratio, $\mathrm{Z}_{\mathrm{O}}=\mathrm{O}^{2-} /\left(\mathrm{OH}^{-}+\mathrm{O}^{2-}\right), \Delta E_{\mathrm{ZO}}$, for methanol, ethanol, and cyclohexane are also given. The $\Delta E_{\mathrm{ZO}}$ values will be discussed later. $\Delta E_{\mathrm{aUp} 1}$ was in the $0.212-0.035 \mathrm{eV}$ range, while $\Delta E_{\mathrm{aDown} 1}, \Delta E_{\mathrm{aUp} 2}$ and $\Delta E_{\mathrm{aDown} 2}$ were in the $0.038-0.012 \mathrm{eV}$ range, and $Y_{\mathrm{OUp} 1}$ was in the $(5.77-0.22) \times 10^{-8}$ range, with all units corresponding to the number of emitted electrons per photon. The following behavior was observed: (a) $\Delta E_{\mathrm{aUp} 1}$ was strongly environment-dependent and was considerably higher than $\Delta E_{\mathrm{aDown} 1}, \Delta E_{\mathrm{aUp} 2}$ and $\Delta E_{\text {aDown2, }}$ except in the case of acetone and benzene, for which all of the $\Delta E_{\mathrm{a}}$ values were nearly the same. (b) $\Delta E_{\mathrm{aUp} 1}$ for the different environments satisfied the following: acetone $<$ benzene $<$ ethanol $<$ cyclohexane $<$ water $<$ methanol $<$ air. The value of $\Delta E_{\mathrm{aUp} 1}$ for the unscratched sample was situated between those for the samples scratched in benzene and ethanol. (c) $\Delta E_{\mathrm{aDown} 1}, \Delta E_{\mathrm{aUp} 2}$ and $\Delta E_{\mathrm{aDown} 2}$ were almost the same across all environments, but the values for water, benzene, and cyclohexane were somewhat higher than the values for air, methanol, ethanol, and acetone. (d) $Y_{\mathrm{OUp} 1}$ was considerably high for air, methanol, and water, but extremely low for acetone and benzene. Furthermore, strikingly, for all environments the plots of $Y_{\mathrm{OUp} 1}$ vs. $\Delta E_{\mathrm{aUp} 1}$ exhibited a parabolic dependence on $\Delta E_{\mathrm{aUp} 1}$. Here, it should be noted that the values of $Y_{\mathrm{GC}}$ shown in Fig. 7 and accordingly those of the Arrhenius activation energy and the pre-exponential factor listed in Table 2 were estimated from the experimental data, except for the background count rate. The count rates of the wavelength scans measured from $289.8 \mathrm{~nm}(4.278 \mathrm{eV})$ to $260 \mathrm{~nm}(4.768 \mathrm{eV})$ at 25,200 , 
(a)
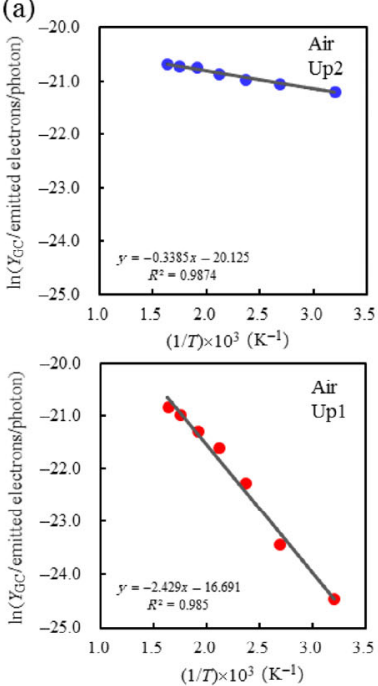

(d)
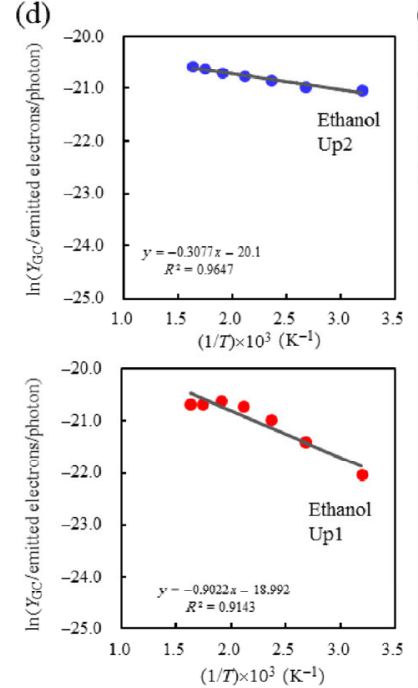

(g)
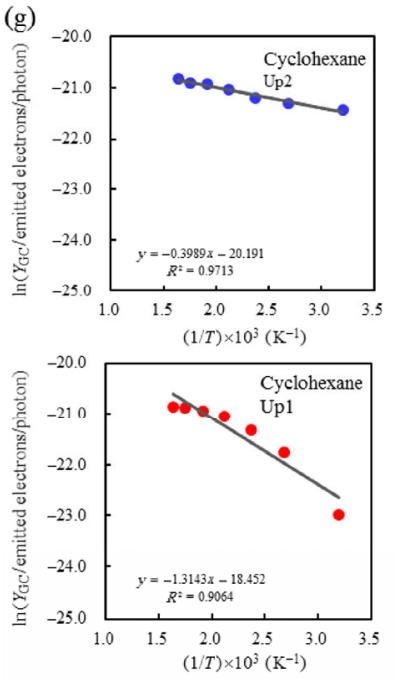

(b)
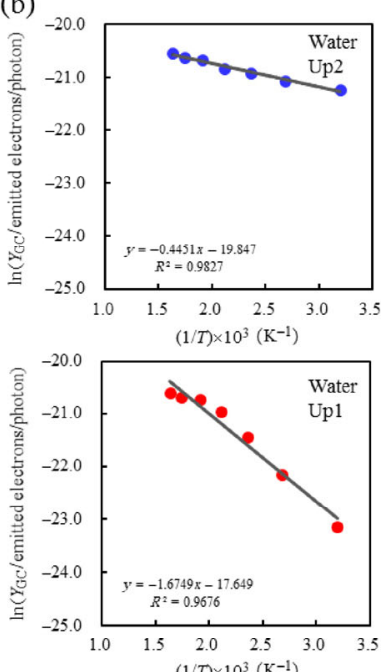

(e)
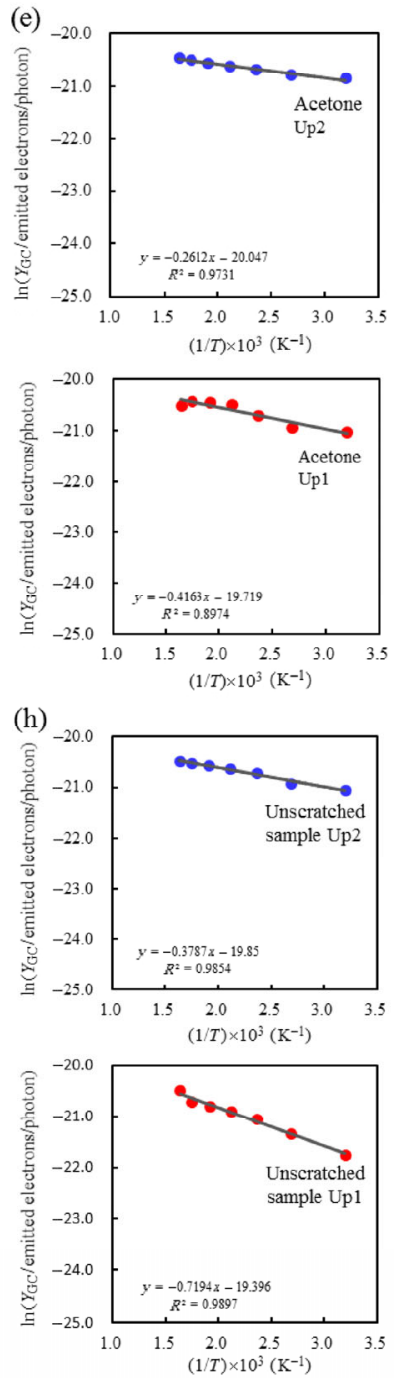

(c)
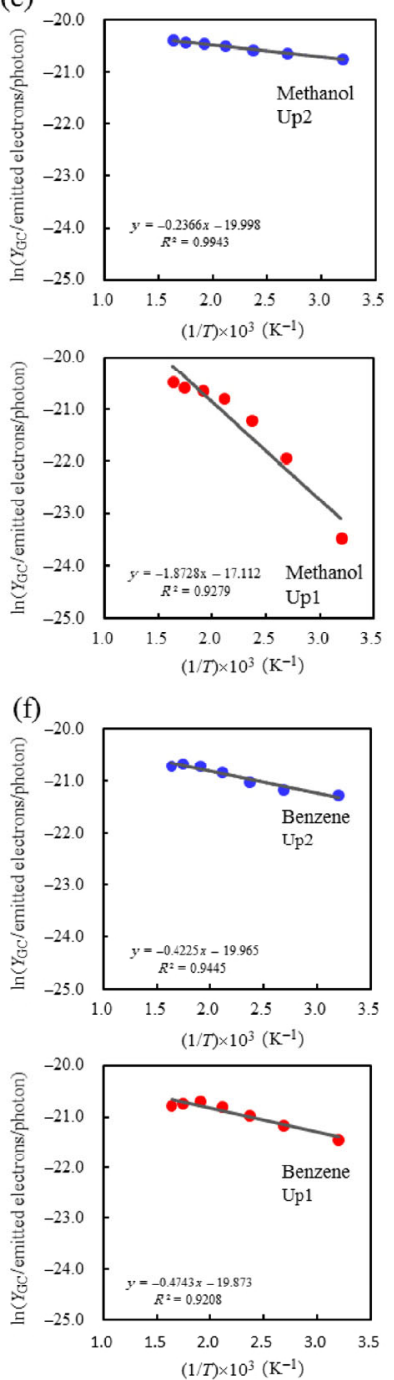

Fig. 7 Plots of $\ln \left(\mathrm{PE}\right.$ quantum yield, $Y_{\mathrm{GC}}$ ) against the reciprocal of temperature in kelvins chosen from the glow curves during the Up1 and Up2 scans for the scratched (a-g) and unscratched (h) samples. The environments were (a) air, (b) water, (c) methanol, (d) ethanol, (e) acetone, (f) benzene, and (g) cyclohexane. The equations and $R^{2}$ of the fitted straight lines are given in the figures. The chosen temperatures were $40,100,150,200,250,300$, and $339^{\circ} \mathrm{C}$. 
Table 2 Activation energies and pre-exponential factors of the thermally assisted PE yields, $Y_{\mathrm{GC}}$, obtained from the glow curves of the Up1, Down1, Up2, and Down2 scans and activation energies of the oxygen component ratio, $Z_{\mathrm{O}}=\mathrm{O}^{2-} /\left(\mathrm{OH}^{-}+\mathrm{O}^{2-}\right)$ for the different environments.

\begin{tabular}{|c|c|c|c|c|c|c|}
\hline $\begin{array}{l}\text { Scratching } \\
\text { environment }\end{array}$ & $\begin{array}{l}\text { Activation energy } \\
\text { in } \mathrm{Up} 1 \text { scan } \\
\left(\Delta E_{\mathrm{aUp} 1} / \mathrm{eV}\right)\end{array}$ & $\begin{array}{l}\text { Activation energy } \\
\text { in Down1 scan } \\
\left(\Delta E_{\mathrm{aDown} 1} / \mathrm{eV}\right)\end{array}$ & $\begin{array}{l}\text { Activation energy } \\
\text { in } \mathrm{Up} 2 \text { scan } \\
\left(\Delta E_{\mathrm{aUp} 2} / \mathrm{eV}\right)\end{array}$ & $\begin{array}{l}\text { Activation energy } \\
\text { in Down2 scan } \\
\left(\Delta E_{\mathrm{aDown} 2} / \mathrm{eV}\right)\end{array}$ & $\begin{array}{c}\text { Pre-exponential factor } \\
\text { in Up1 scan }\left(Y_{0 \mathrm{Up} 1} /\left(10^{-8}\right.\right. \\
\text { emitted electrons/photon }))\end{array}$ & $\begin{array}{c}\text { Activation } \\
\text { energy of } Z_{\mathrm{O}} \\
\left(\Delta E_{\mathrm{ZO}} / \mathrm{eV}\right)\end{array}$ \\
\hline Air & 0.212 & 0.022 & 0.028 & 0.016 & 5.77 & \\
\hline Water & 0.145 & 0.031 & 0.038 & 0.031 & 2.13 & \\
\hline Methanol & 0.159 & 0.012 & 0.020 & 0.017 & 3.41 & 0.023 \\
\hline Ethanol & 0.079 & 0.017 & 0.026 & 0.020 & 0.56 & 0.032 \\
\hline Acetone & 0.035 & 0.016 & 0.021 & 0.019 & 0.26 & \\
\hline Benzene & 0.039 & 0.028 & 0.035 & 0.027 & 0.22 & \\
\hline Cyclohexane & 0.111 & 0.029 & 0.033 & 0.030 & 0.89 & 0.043 \\
\hline Unscratched & 0.062 & 0.021 & 0.033 & 0.023 & 0.38 & \\
\hline
\end{tabular}

and $339^{\circ} \mathrm{C}$ were used to determine the background count rates for the scratched samples in the $25-339{ }^{\circ} \mathrm{C}$ range of temperatures. In this range of wavelengths, the count rate was constant, which confirmed no PE emission from the samples. The background rate for the scratched samples was in the range of $150-408$ counts/min. For the unscratched sample, the wavelength scan data in Ref. [6] were used and the background rate was in the range of $182-248$ counts/min.

Considering that the $\Delta E_{\mathrm{a}}$ obtained from the Up1 scan was significantly different from the values obtained from the other scans, as listed in Table 2, the effect of the interaction of the real iron surface with the different environments during scratching was reflected only in the PE of the Up1 scan up to $339^{\circ} \mathrm{C}$. The surface overlayer, which contains oxides, hydroxyl groups, and other reaction products, is considered to be environment-dependent. This environment dependence of $\Delta E_{\mathrm{aUp} 1}$ will be explained later, based on the acid-base interaction. In contrast, during the Down1, Up2, and Down2 scans the surface overlayer was considered to preferentially contain surface oxides grown during the heating to $339^{\circ} \mathrm{C}$ in the Up1 scan. The finding that $\Delta E_{\mathrm{aDown} 1}, \Delta E_{\mathrm{aUp} 2}$ and $\Delta E_{\mathrm{aDown} 2}$ were nearly constant across the different environments may suggest that a thermally stabilized structure emerged when heating to the final temperature during the Up1 scan, and this structure persisted. The relation between $\Delta E_{\mathrm{aUp} 2}$ and the intensities of the $\mathrm{FeO}$ and $\mathrm{Fe}_{2} \mathrm{O}_{3}$ components of the $\mathrm{Fe} 3 \mathrm{p}$ spectra observed after heating at $339{ }^{\circ} \mathrm{C}$ will be described later. We believe that the values of
$\Delta E_{\mathrm{aDown} 1}, \Delta E_{\mathrm{aUp} 2}$, and $\Delta E_{\mathrm{aDown} 2}$ may be associated with the transport of electrons through the oxide layer. However, for the Down1, Up2, and Down2 scans, $\Delta E_{\mathrm{a}}$ was very close to the difference between the thermal energy values represented by $k_{\mathrm{B}} \mathrm{T}$ at $25^{\circ} \mathrm{C}$ and $339^{\circ} \mathrm{C}$, $0.025 \mathrm{eV}$ and $0.053 \mathrm{eV}$, respectively, which equals $0.028 \mathrm{eV}$. Therefore, the activation energy obtained from the Down1, Up2, and Down2 scans may also originate from thermal excitation of electrons in the proximity of the Fermi level of the metal itself.

\subsection{Temperature dependence of XPS results for scratched real iron surfaces}

Figures 8 and 9 show the surface O1s and C1s composition and the intensity of the four Fe3p components, respectively, at 25,200 , and $339^{\circ} \mathrm{C}$. The surface composition was determined from the O1s, $\mathrm{C} 1 \mathrm{~s}$, and Fe3p spectra, and the Fe3p components corresponded to the $\mathrm{Fe}$ metal, $\mathrm{FeO}, \mathrm{Fe}_{2} \mathrm{O}_{3}$, and $\mathrm{FeOOH}$. The following conclusions can be made by inspecting Fig. 8(a) regarding the environment dependence of the $\mathrm{O} 1 \mathrm{~s}$ and $\mathrm{C} 1 \mathrm{~s}$ compositions at 25 and $339{ }^{\circ} \mathrm{C}$, at $25{ }^{\circ} \mathrm{C}$ the $\mathrm{O} 1 \mathrm{~s}$ composition decreased from $36.8 \%$ (water) to $23.7 \%$ (cyclohexane), while the $\mathrm{C} 1 \mathrm{~s}$ composition gradually increased from $49.0 \%$ (water) to $64.3 \%$ (cyclohexane). In contrast, at $339{ }^{\circ} \mathrm{C}$ the $\mathrm{O} 1 \mathrm{~s}$ composition shifted from $36.5 \%$ (benzene) to $42.6 \%$ (acetone), and the $\mathrm{C} 1 \mathrm{~s}$ composition increased from $39.3 \%$ (acetone) to $49.3 \%$ (benzene). Thus, the changes in the $\mathrm{O} 1 \mathrm{~s}$ and $\mathrm{C} 1 \mathrm{~s}$ compositions at $25^{\circ} \mathrm{C}$ were much stronger than those at $339^{\circ} \mathrm{C}$. This means that the 

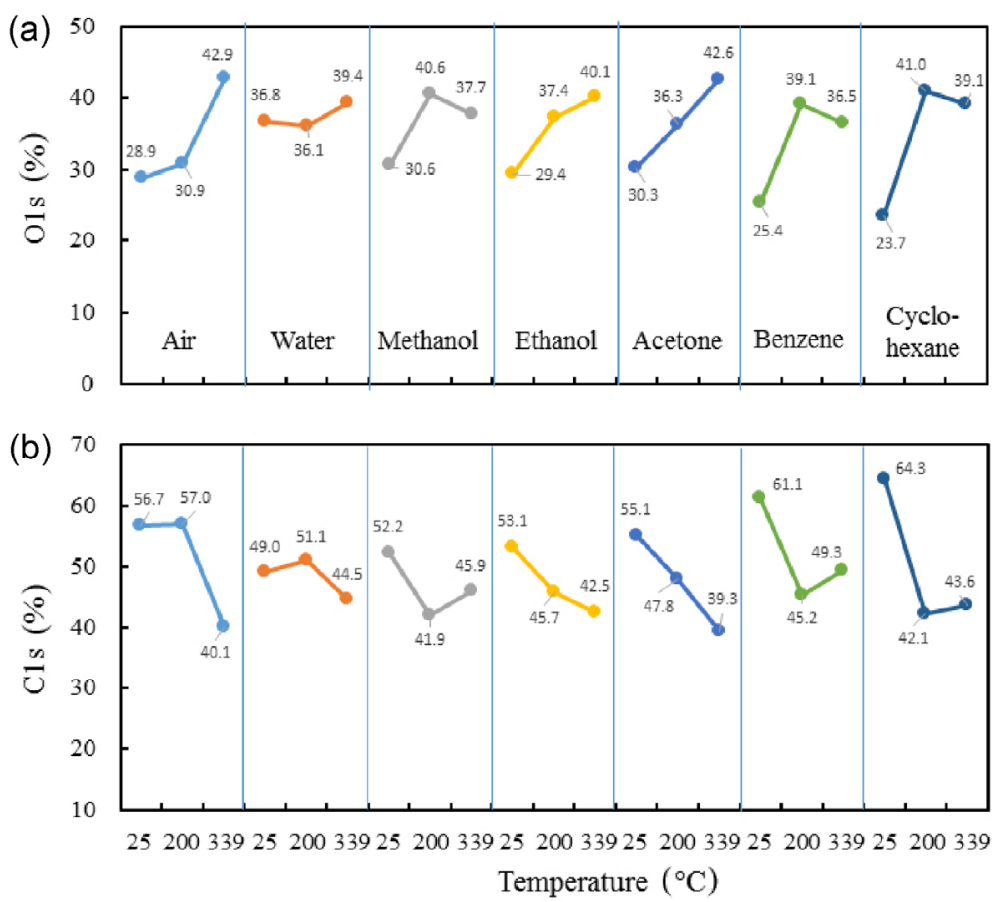

Fig. 8 Percentage of O1s (a) and $\mathrm{C} 1 \mathrm{~s} \mathrm{(b)} \mathrm{surface} \mathrm{compositions} \mathrm{at} 25,200$, and $339^{\circ} \mathrm{C}$, for samples scratched in the environments indicated in the top figure.
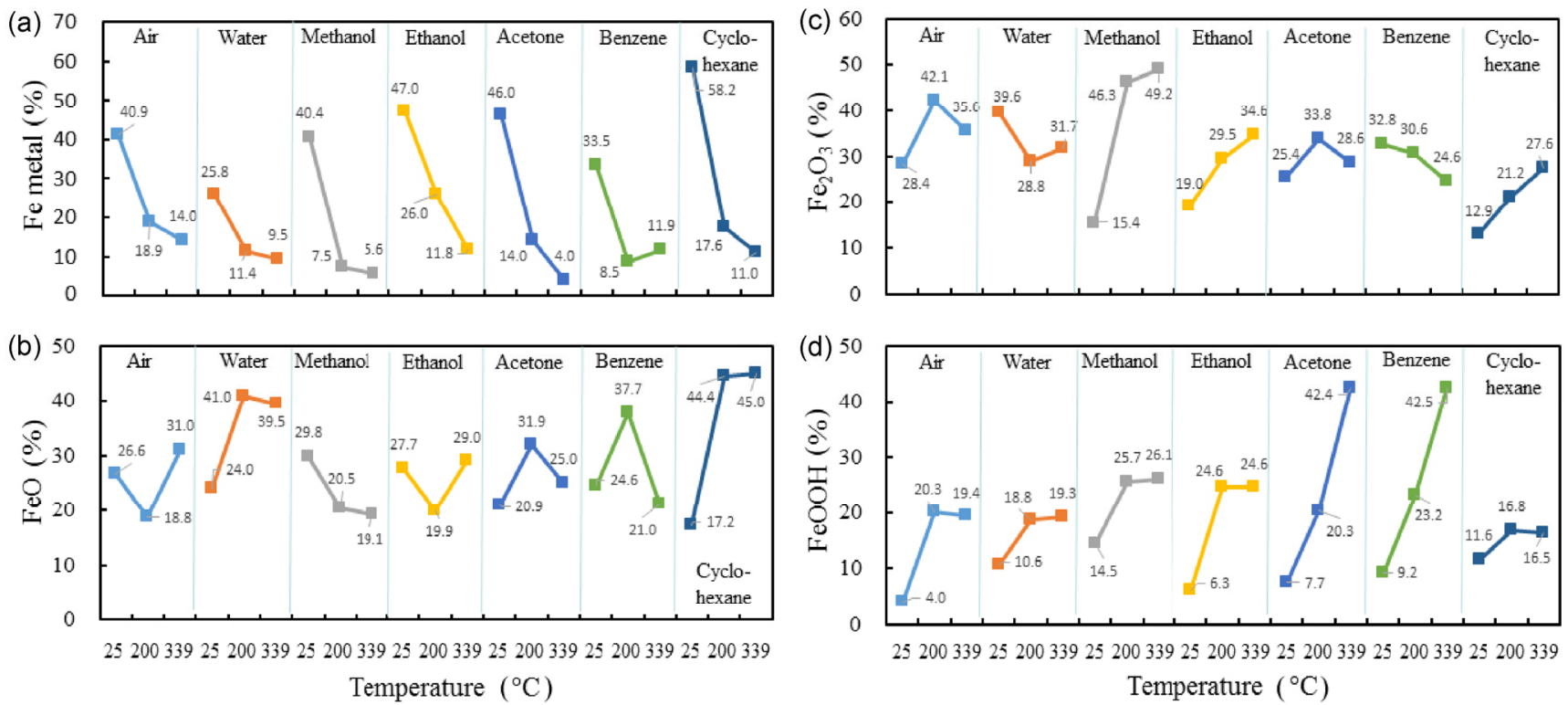

Fig. 9 Percentage of four $\mathrm{Fe} 3 \mathrm{p}$ components at 25,200 , and $339^{\circ} \mathrm{C}$, for samples scratched in the environments indicated in the figure: (a) $\mathrm{Fe}$ metal, (b) $\mathrm{FeO}$, (c) $\mathrm{Fe}_{2} \mathrm{O}_{3}$, and (d) $\mathrm{FeOOH}$.

effect of scratching in the liquid environments on the surface compositions of the samples was much stronger at the lower temperature than that at the higher temperature. (b) At $25^{\circ} \mathrm{C}$ and $200{ }^{\circ} \mathrm{C}$, there was little change in the $\mathrm{O} 1 \mathrm{~s}$ and $\mathrm{C} 1 \mathrm{~s}$ compositions for the samples scratched in air and water, while in the case of the other environments, the O1s composition increased and the C1s composition decreased more clearly. This finding implies that, compared with the other environments, in the case of air and water oxygen species and carbon materials were stronger bound to the metal surface. (c) As the temperature increased 
from $200{ }^{\circ} \mathrm{C}$ to $339^{\circ} \mathrm{C}$, in the case of air, water, ethanol, and acetone, the O1s composition increased and the C1s composition decreased, while the opposite trend was observed for methanol, benzene, and cyclohexane. This finding suggests that the ability of oxygen species and carbon materials to remain on the sample surface for temperatures in the $200-339^{\circ} \mathrm{C}$ range was different in the different environments. The effect of co-adsorbed oxygen species and carbon materials on the convex swelling peak observed in the Up1 scan PE glow curves will be described later.

In Fig. 9, we focused on analyzing the intensity of the $\mathrm{FeO}$ and $\mathrm{Fe}_{2} \mathrm{O}_{3}$ components at $339^{\circ} \mathrm{C}$. The intensity of both oxides formed at $339{ }^{\circ} \mathrm{C}$ was strikingly environment-dependent. The $\mathrm{FeO}$ intensities for the different environments satisfied the following relation: methanol $<$ benzene $<$ acetone $<$ ethanol $<$ air $<$ water $<$ cyclohexane, while the $\mathrm{Fe}_{2} \mathrm{O}_{3}$ intensities satisfied the following order: benzene $<$ cyclohexane $<$ acetone $<$ water $<$ ethanol $<$ air $<$ methanol. The relationship between these orders and both $\Delta E_{\mathrm{aUp} 2}$ and the total count of electrons emitted during the Up2 scan will be discussed later.

\section{Discussion}

\subsection{Activation energy of PE in the Up1 scan}

It is believed that $\Delta E_{\mathrm{aUp} 1}$ was determined by the surface interactions on the surface overlayer formed during scratching in the selected environments and its temperature dependence. We have examined the dependence of $\Delta E_{\mathrm{aUp} 1}$ on the total count of electrons emitted during the Up1 scan and the acid-base interactions in liquid environments. Figure 10 shows the relationship between the total count of electrons emitted during the Up1 scan and $\Delta E_{\mathrm{aUp} 1}$, for the different environments. Interestingly, the total count of emitted electrons decreased approximately linearly with increasing $\Delta E_{\mathrm{aUp} 1}$. This finding reveals that the thermal activation process importantly shapes the PE intensity.

We reconsidered the two roles of the surface overlayer in the PE mentioned above, based on the values of $\Delta E_{\mathrm{aUp} 1}$ and $\Delta E_{\mathrm{ZO}}$ for methanol, ethanol, and cyclohexane listed in Table 2 . The oxygen component

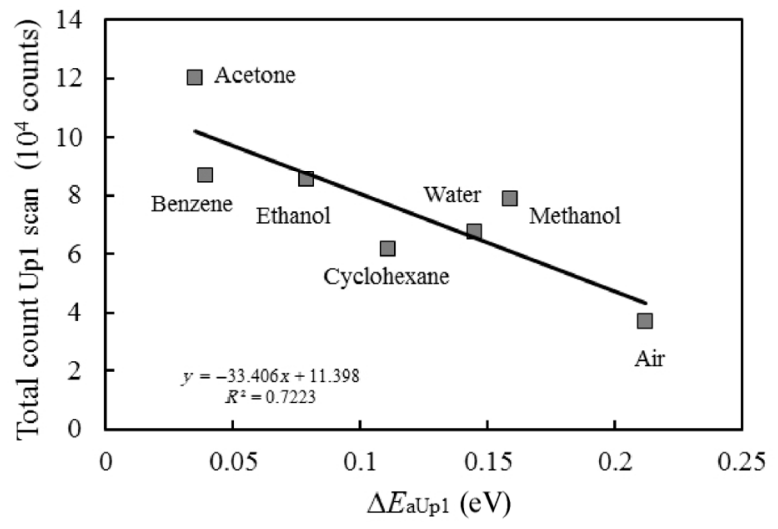

Fig. 10 Plots of the total count of electrons emitted during the Up1 scan vs. the activation energy obtained from the Up1 scan, $\Delta E_{\mathrm{aUp} 1}$, for the different environments. The equation and $R^{2}$ of the fitted straight line are given in the figure.

ratio $Z_{\mathrm{O}}$ is given by $\mathrm{Z}_{\mathrm{O}}=\mathrm{O}^{2-} /\left(\mathrm{OH}^{-}+\mathrm{O}^{2-}\right)$. The $\Delta E_{\mathrm{ZO}}$ values were obtained from the straight line in the Arrhenius plot of $\ln \left(Z_{\mathrm{O}}\right)$ against $1 / T$. The $\Delta E_{\mathrm{ZO}}$ values for methanol and cyclohexane were reported previously [7], while that for ethanol was obtained in the present study. For these environments, $\Delta E_{\mathrm{aUp} 1}$ was much higher than the $\Delta E_{\mathrm{ZO}}$. In a previous paper [6], it was concluded, based on the similarity between the $\Delta E_{\mathrm{a}}$ and $\Delta E_{\mathrm{O}}$ values for real iron surfaces cleaned only in acetone, that the penetration of the incident light through the surface overlayer is the first step in the PE process. The present case, however, suggests that $\Delta E_{\mathrm{aUp} 1}$ cannot be attributed only to $Z_{\mathrm{O}}$. Therefore, we think that $\Delta E_{\mathrm{aUp} 1}$ may be related to the transfer of electrons excited in the metal to the surface overlayer and subsequent transport through the overlayer, rather than to the penetration of incident light.

As suggested by Table 2, for all environments the plots of $Y_{0 \mathrm{Up} 1}$ vs. $\Delta E_{\mathrm{aUp} 1}$ exhibited a parabolic increase of $Y_{\text {oUp1 }}$ with $\Delta E_{\mathrm{aUp} 1}$. This behavior may be explained by the ability of the overlayer formed during scratching in the different environments to hold electrons. The TAPE process is considered as follows: first, excited electrons are formed in the light-irradiated area on the metal surface; next, the transfer of the excited electrons to the overlayer and their subsequent transport through the overlayer occur. Therefore, it is presumed that, in the case of air (which yields the highest $\Delta E_{\mathrm{aUp1}}$ ), the excited electrons may be strongly bound in the light-irradiated area of the overlayer, so that the transfer and transport of excited electrons 
becomes difficult, while in the case of acetone (which yields the lowest $\Delta E_{\mathrm{aUp} 1}$ ), the excited electrons may be loosely bound in the irradiated area, allowing them to move easily. Thus, in the case of air, the values of both $Y_{0 \mathrm{Up} 1}$ and $\Delta E_{\mathrm{aUp} 1}$ are higher than those in the case of acetone.

Regarding the thickness effect of the overlayer on $\Delta E_{\mathrm{aUp} 1}$, we considered that the amount of the percentage reduction in the $\mathrm{Fe}$-metal (\%) from $25^{\circ} \mathrm{C}$ to $339^{\circ} \mathrm{C}$ (that is, $\Delta$ Fe-metal $(\%)=$ Fe-metal at $25^{\circ} \mathrm{C}-$ Fe-metal at $339^{\circ} \mathrm{C}$ ) may be related to $\Delta E_{\mathrm{aUp} 1}$, because $\Delta \mathrm{Fe}$-metal is equal to the increase in the sum of $\mathrm{FeO}(\%), \mathrm{Fe}_{2} \mathrm{O}_{3}(\%)$, and $\mathrm{FeOOH}(\%)$ from $25{ }^{\circ} \mathrm{C}$ to $339^{\circ} \mathrm{C}$. We examined the relationship between $\Delta E_{\mathrm{aUp} 1}$ and $\Delta$ Fe-metal (\%) using the Fe-metal values shown in Fig. 9(a). In the case of water (with $\Delta E_{\mathrm{aUp} 1}=0.145 \mathrm{eV}$ ), Fe-metal (\%) reduced from 25.8 to 9.5 , becoming $\Delta$ Fe-metal $(\%)=$ 16.3 , while in the case of $\mathrm{C}_{6} \mathrm{H}_{12}$ (with $\Delta E_{\mathrm{aUp} 1}=0.111 \mathrm{eV}$ ), Fe-metal (\%) reduced from 58.2 to 11.0, becoming $\Delta$ Fe-metal $(\%)=47.2$. This finding suggests that the relation between $\Delta \mathrm{Fe}$-metal and $\Delta E_{\mathrm{aUp} 1}$ is weak. We posit that the chemical and electrical properties of the overlayer more strongly affect $\Delta E_{\mathrm{aUp} 1}$ than the overlayer's thickness.

\subsection{Effect of acid-base properties of liquids mole- cules on PE in the Up1 scan}

Figures 11(a) and 11(b) show the dependence of $\Delta E_{\mathrm{aUp} 1}$ on the acceptor number [9] and proton affinity [10] of the liquid environment, respectively. Interestingly, $\Delta E_{\mathrm{aUp} 1}$ increased with increasing acceptor number, but tended to decrease with increasing proton affinity, although the data points were rather scattered. This finding indicates that molecules with higher acceptor number suppressed the PE intensity, while molecules with higher proton affinity promoted the PE intensity. Based on the acid-base properties of molecules, we propose that the effect of electric charges formed in the overlayer is among the most important surface properties affecting the PE. In our previous study [7], based on the work of Bolger and Michaels [11], we explained the acid-base interaction of surface hydroxyl groups $(-\mathrm{MOH})$ with the environment molecules. The interaction mode can be changed by varying the acid-base properties of the molecules, but as described later, the electron density of the oxygen atom of $-\mathrm{MOH}$ can also play an important role in the acid-base interaction. In the present experiment, $\mathrm{MOH}$ was represented by $\mathrm{FeOH}$ from the $\mathrm{FeO}(\mathrm{OH})$ component. We examined the surface interactions between the $\mathrm{FeOH}$ and the different liquid environments based on their acceptor number, which represents the Lewis acidity or electrophilicity of a solvent, and proton affinity, which represents a measure of the tendency of a sample molecule to accept a proton or the gas-phase basicity.

Figure 12 shows examples of orientations of electric dipoles formed by the acid-base interaction modes between the molecules of $\left(\mathrm{CH}_{3}\right)_{2} \mathrm{CO}, \mathrm{C}_{2} \mathrm{H}_{5} \mathrm{OH}$, and $\mathrm{H}_{2} \mathrm{O}$, and the surface hydroxyl groups, based on Ref. [11]. In Fig. 12, as the molecules are considered from left to right, the acceptor number increases (Fig. 12(a)) and the proton affinity increases (Fig. 12(b)). We explain the interaction modes of $\mathrm{H}_{2} \mathrm{O}$, which has the highest acceptor number, and $\left(\mathrm{CH}_{3}\right)_{2} \mathrm{CO}$, which has the highest proton affinity, with $\mathrm{FeOH}$. In the case of
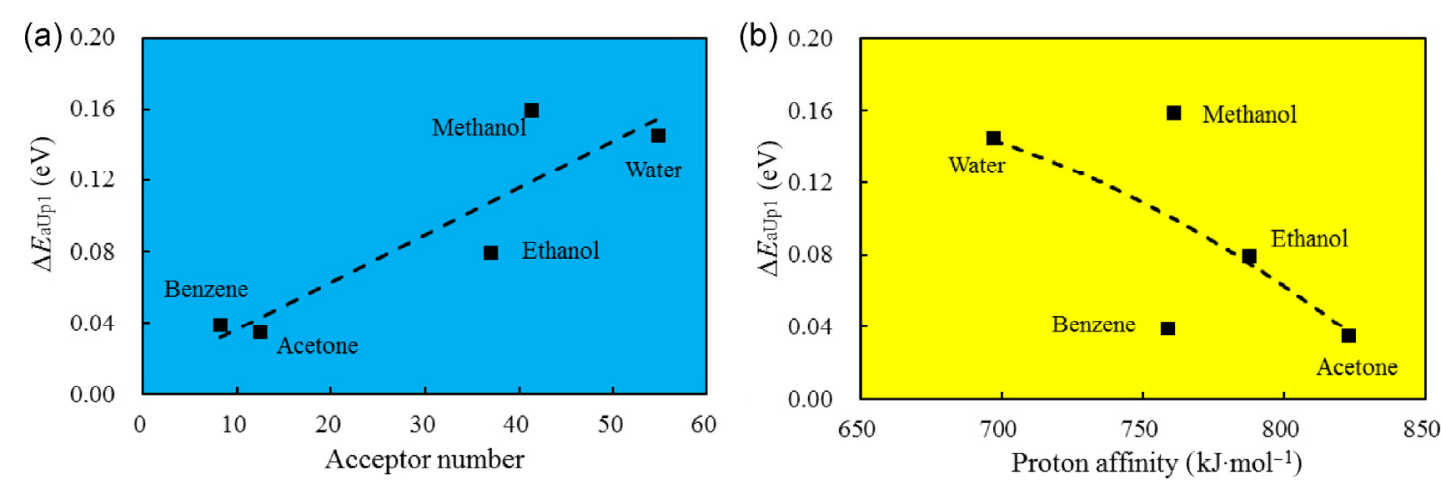

Fig. 11 Relationship between the activation energy, $\Delta E_{\mathrm{aUp}}$, from the Up1 scan and the acceptor number (a) and the proton affinity (b) of the molecules of liquid environments. 
(a) Interaction mode based on the acceptor number of the liquid molecules which increases from left to right.

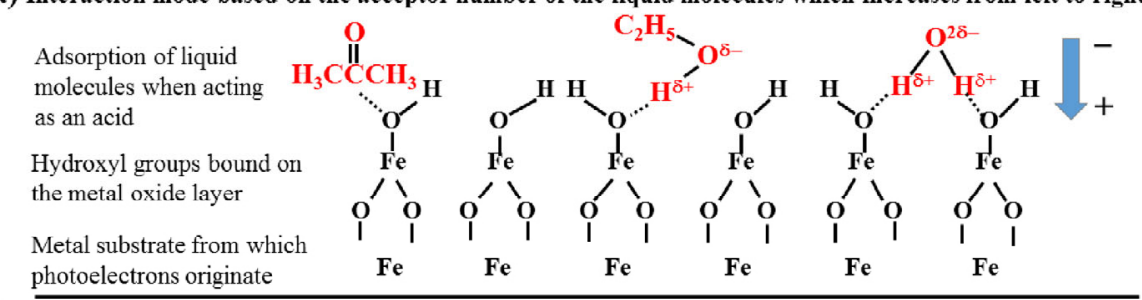

(b) Interaction mode based on the proton affinity of the liquid molecules which increases from left to right.

Adsorption of liquid
molecules when
acting as a base
Hydroxyl groups bound on
the metal oxide layer

Fig. 12 Examples of orientations of electric dipoles formed by the acid-base interaction modes between the molecules of $\left(\mathrm{CH}_{3}\right)_{2} \mathrm{CO}$, $\mathrm{C}_{2} \mathrm{H}_{5} \mathrm{OH}$, and $\mathrm{H}_{2} \mathrm{O}$ and the surface hydroxyl groups $(\mathrm{Fe}-\mathrm{OH})$ based on: (a) the acceptor number, which represents the strength of the acidity, and (b) the proton affinity, which quantifies the tendency of a sample molecule to accept a proton or the gas-phase basicity. The former mode increases $\Delta E_{\mathrm{aUp} 1}$ and the latter decreases $\Delta E_{\mathrm{aUp} 1}$. The dotted lines in the figure indicate the hydrogen bond, although the interaction mode for acetone as an acid is unclear.

$\mathrm{H}_{2} \mathrm{O}$ (Fig. 12(a)), the $\mathrm{H}$ atom of $\mathrm{H}_{2} \mathrm{O}$ is attracted to the unshared electron pair of the $\mathrm{O}$ atom of $\mathrm{FeOH}$, producing an electric dipole with its negatively charged end oriented toward the outside, represented by $\mathrm{FeOH} \cdots \mathrm{H}^{\delta_{+}}-\mathrm{OH}^{\delta-}$. In the case of $\left(\mathrm{CH}_{3}\right)_{2} \mathrm{CO}$ (Fig. 12(b)), the $\mathrm{H}$ atom of $\mathrm{FeOH}$ is attracted to the unshared electron pair of the $\mathrm{O}$ atom of $\left(\mathrm{CH}_{3}\right)_{2} \mathrm{CO}$, producing an electric dipole with its positively charged end oriented toward the outside, represented by $\mathrm{FeO}^{\delta-}$ $\mathrm{H}^{\delta_{+}} \ldots \mathrm{O}=\mathrm{C}\left(\mathrm{CH}_{3}\right)_{2}$. Here, the symbol ( ..) denotes the hydrogen bond. Thus, these orientations of the electric charges contribute to the increase or reduction in $\Delta E_{\mathrm{aUp} 1}$, respectively, which significantly affects the PE intensity. In addition, the finding that the total count of electrons emitted in the Up1 scan is low in the case of water, but high in the case of acetone (Fig. 10) can be reasonably explained in terms of these electric charge orientation modes. In addition, we examined the relationship between $\Delta E_{\mathrm{aUp} 1}$ and the dielectric constants $\left(\varepsilon / \varepsilon_{0}\right)$ [12] of the liquids: $\mathrm{H}_{2} \mathrm{O}\left(\Delta E_{\mathrm{aUp} 1}=\right.$ $\left.0.145 \mathrm{eV}, \varepsilon / \varepsilon_{0}=81.7\right), \mathrm{CH}_{3} \mathrm{OH}(0.159 \mathrm{eV}, 32.6), \mathrm{C}_{2} \mathrm{H}_{5} \mathrm{OH}$ (0.079 eV, 24.3), $\left(\mathrm{CH}_{3}\right)_{2} \mathrm{CO}(0.035 \mathrm{eV}, 20.7)$, and $\mathrm{C}_{6} \mathrm{H}_{6}$ $(0.039 \mathrm{eV}, 2.3)$. The plots of $\Delta E_{\mathrm{aUp} 1}$ vs. $\varepsilon / \varepsilon_{0}$ for the different liquids revealed the tendency of $\Delta E_{\mathrm{aUp} 1}$ to increase with $\varepsilon / \varepsilon_{0}$. This suggests that in the case of water and methanol the value of $\Delta E_{\mathrm{aUp} 1}$ during the Up1 scan may be associated with the liquid's electrical polarization, although the mechanism remains unclear.

\subsection{Convex swelling peak in the PE glow curves in the Up1 scan}

The PE glow curves observed in the Up1 scan for all environments (Fig. 1 in Ref. [7]) are shown on the same plot in Fig. 13. Convex swelling peaks with different intensities are apparent in all glow curves. The appearance of these environment-dependent convex swelling peaks proves that the effects of liquid

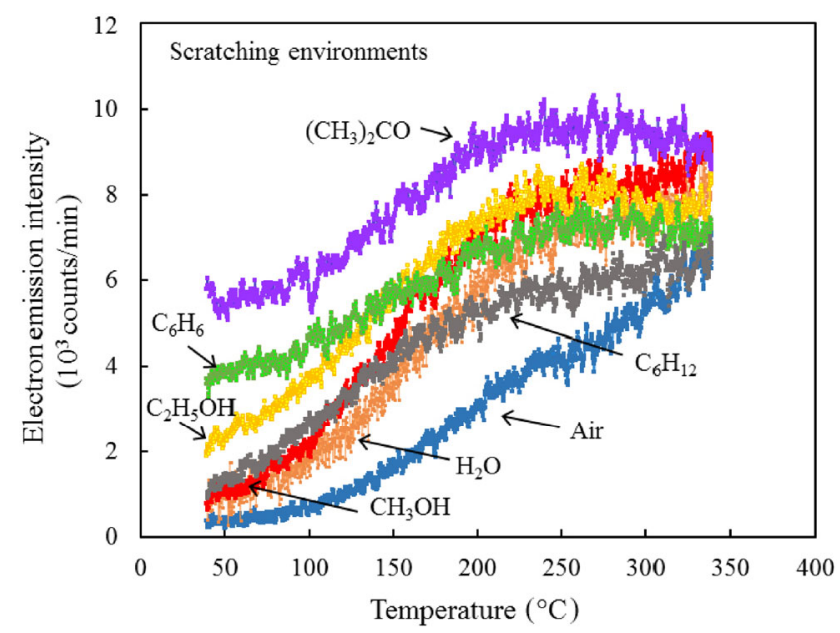

Fig. 13 Photoelectron emission glow curves observed during the Up1 scans, for the different environments. 
environments on the scratched surfaces persist up to the temperatures of $\sim 300{ }^{\circ} \mathrm{C}$, even if the adsorbed liquids are partially evaporated. The presence of these convex swelling peaks may have been caused by the following two emission modes: (a) the direct emission of the electrons excited from the metal base without being trapped in the overlayer and (b) the emission of electrons via electron trapping sites formed in the overlayer after their excitation by the incident light. In fact, the glow curves are considered to include the electrons emitted via both emission routes, although the mechanism remains unclear [7].

We examined more deeply the mechanisms underlying the convex swelling peaks, emphasizing the effects of surface-bound carbon materials and electron density on the oxygen atom of the $\mathrm{Fe}-\mathrm{OH}$ group under the irradiation by light. First, we considered the effect of the surface composition (Fig. 8) on the PE. The magnitude of the swelling of the glow curve, MSG, was defined, for comparing the environment dependence of the MSG to that of the C1s composition shown in Fig. 8(b). For each Up1 scan PE glow curve, a straight line was drawn to connect the electron emission intensities at $40{ }^{\circ} \mathrm{C}$ and $339^{\circ} \mathrm{C}$, and the emission intensities at 40,100, 150, 200, 250, 300 , and $339^{\circ} \mathrm{C}$ were estimated from this straight line by interpolation. Each of these emission intensities was then subtracted from the actual emission intensity observed at the same temperature. The difference between the two emission intensities yielded the MSG. The idea of drawing a straight line between the electron emission intensities at $40{ }^{\circ} \mathrm{C}$ and $339^{\circ} \mathrm{C}$ in the PE glow curve came from the results obtained for the wavelength scans from $300 \mathrm{~nm}$ to $200 \mathrm{~nm}$ and measured at 25,200 , and $339{ }^{\circ} \mathrm{C}$. These results were as follows: (a) the total count of electrons emitted during the wavelength scans increased approximately linearly with temperature. (b) The plots of the total count of emitted electrons vs. temperature were qualitatively similar for all environments. Thus, the PE intensity measured in the wavelength scans was assumed to be unaffected by the environment and the internal photoelectric effect, which can be speculated to have occurred under the continual light irradiation at $210 \mathrm{~nm}$ during the PE glow curve measurements.

Figure 14 shows the plots of MSG vs. temperature. Except in the case of air, all plots feature a broad

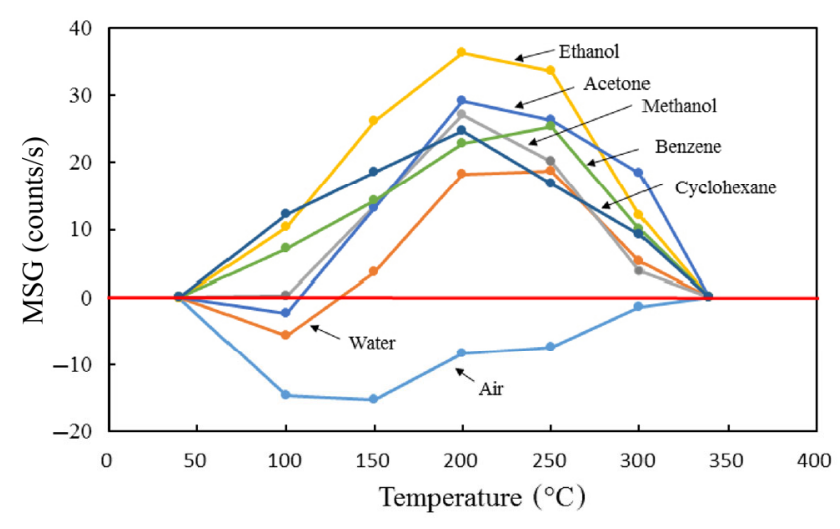

Fig. 14 Plots of the magnitudes of swelling of the glow curves, MSG, during the Up1 scans, vs. selected temperatures from the glow curves in Fig. 13. The value of MSG was defined as the difference between the emission intensity at the selected seven temperatures in the observed glow curves and that on the straight line drawn between the intensities at $40{ }^{\circ} \mathrm{C}$ and $339^{\circ} \mathrm{C}$, which is represented by the red horizontal axis.

peak in the temperature range of $100-300{ }^{\circ} \mathrm{C}$. In the case of air, the MSG values are negative over the entire range of temperatures. In Fig. 14 , at $200{ }^{\circ} \mathrm{C}$ the MSG for the different environment increases in the following order: air $<$ water $<$ benzene $\leq$ cyclohexane $\leq$ methanol $\leq$ acetone $<$ ethanol, while in Fig. $8(\mathrm{~b})$, the $\mathrm{C} 1 \mathrm{~s}$ intensities for the different environments, measured at $200{ }^{\circ} \mathrm{C}$, in the order of increasing MSG, are as follows: air $(\mathrm{C} 1 \mathrm{~s}$ intensity $=57.0 \%)>$ water $(51.1 \%)>$ benzene $(45.2 \%) \approx$ cyclohexane $(42.1 \%) \approx$ methanol $(41.9 \%) \approx$ acetone $(47.8 \%) \approx$ ethanol $(45.7 \%)$. This order indicates that the $\mathrm{C} 1 \mathrm{~s}$ intensities for air and water were considerably higher than those for the organic environments, which were almost the same. This finding suggests that the thermal removal of carbon materials occurred more easily from samples scratched in organic environments, resulting in the exposure of the inner layer, while the carbon materials were more strongly bound to the surfaces of samples that were scratched in air, and acted to suppress the convex swelling peak.

In general, when solids are irradiated with light, electrical effects such as the external photoelectric effect (called photoemission or PE) and internal effects (such as photoconduction) can be observed. The temperature dependence of the PE intensity under irradiation with the wavelength of $210 \mathrm{~nm}$ was significantly different across the different environments (Fig. 13), while the 
total count of electrons emitted during the wavelength scan was approximately the same. Therefore, we posit that, as an internal photoelectric effect, the electron density on the $\mathrm{O}$ atom of $\mathrm{Fe}-\mathrm{OH}$ may be increased during irradiation with light, enhancing the acid-base interaction of $\mathrm{Fe}-\mathrm{OH}$ with the molecules of the liquid environment. Momose et al. [13] reported the effect of light on optically stimulated exoelectron emission (OSEE) from commercial aluminum surfaces, which was measured using a Geiger counter with a counter gas consisting of $\mathrm{Ar}$ and a small amount of $\mathrm{C}_{2} \mathrm{H}_{5} \mathrm{OH}$ vapor. They found that the plot of the OSEE intensity against the power of the stimulating light exhibited a maximum, and explained that this behavior could be attributed to the alteration of an electric dipole formed by ethanol molecules adsorbed on $\mathrm{Al}-\mathrm{OH}$ of the hydroxylated oxide layer on the metal surface. As the electron density of the $\mathrm{O}$ atom in $\mathrm{Al}-\mathrm{OH}$ increases owing to the irradiation, the ability of the $\mathrm{O}$ atom in $\mathrm{Al}-\mathrm{OH}$ to attract the $\mathrm{H}$ atom in the hydroxyl group of $\mathrm{C}_{2} \mathrm{H}_{5} \mathrm{OH}$ (that is, the basicity of the $\mathrm{O}$ atom of $\mathrm{Al}-\mathrm{OH}$ ) increases. Therefore, the acid-base interaction mode of $\mathrm{C}_{2} \mathrm{H}_{5} \mathrm{OH}$ with $\mathrm{Al}-\mathrm{OH}$ changes from $\mathrm{Al}-\mathrm{O}^{\delta-}-$ $\mathrm{H}^{\delta+} \ldots \mathrm{HOC}_{2} \mathrm{H}_{5}$, in which $\mathrm{C}_{2} \mathrm{H}_{5} \mathrm{OH}$ acts as a base, to $\mathrm{Al}-\mathrm{OH} \cdots \mathrm{H}^{\delta+}-\mathrm{O}^{\delta-} \mathrm{C}_{2} \mathrm{H}_{5}$, in which $\mathrm{C}_{2} \mathrm{H}_{5} \mathrm{OH}$ acts as an acid, producing a maximum in the OSEE intensity.

In the present study, we believe that the acidity or basicity of not only the liquid molecules but also the $\mathrm{Fe}-\mathrm{OH}$ group played an important role in surface interactions. Let us consider the adsorption of water and acetone as examples. Owing to the increase in the electron density of the $\mathrm{O}$ atom in $\mathrm{Fe}-\mathrm{OH}$ under the irradiation, the acidic interaction with water, which has a high acceptor number, is enhanced, leading to a decreased PE intensity, while the basic interaction with acetone, which has a high proton acceptor, becomes much stronger, enhancing the PE intensity, as shown in Figs. 10(a) and 10(c) in Ref. [7]. We previously reported that the oxygen component ratio, $\mathrm{Zo}=\mathrm{O}^{2-} /\left(\mathrm{OH}^{-}+\mathrm{O}^{2-}\right)$, strongly affects the PE intensity depending on the temperature (Fig. 6 in Ref. [7]). In addition, it should be noted that the $\mathrm{OH}^{-}$component is considered to be related mainly to the lattice $\mathrm{OH}^{-}$ (which originates from $\mathrm{Fe}(\mathrm{OH})_{2}$ and $\mathrm{FeOOH}$ ) and adsorbed $\mathrm{OH}$ and $\mathrm{H}_{2} \mathrm{O}$. The $\mathrm{O}^{2-}$ component is attributed to the lattice $\mathrm{O}^{2-}$, which stems from $\mathrm{FeO}, \mathrm{Fe}_{3} \mathrm{O}_{4}$, and
FeOOH $[7,14]$. Therefore, among these surface oxygen species $\mathrm{FeOH}$ plays a more important role in the interaction with the molecules of liquid environments.

We consider the effect of the surface overlayer on the PE intensity observed in the Up1 scan for $\mathrm{C}_{2} \mathrm{H}_{5} \mathrm{OH}$. The following steps are considered: (a) The species such as adsorbed water, surface hydroxyl groups, and carbon materials weakly bound at $25^{\circ} \mathrm{C}$ have little effect on the electron emission intensity. (b) These species gradually desorb with increasing temperature. (c) $\mathrm{FeOH}$ then predominantly forms and its $\mathrm{H}$ atom is attracted to the $\mathrm{O}$ atom from $\mathrm{C}_{2} \mathrm{H}_{5} \mathrm{OH}$ as a base, which creates an electric dipole with its positively charged end oriented outwards, causing an increase in the electron emission intensity. (d) Finally, a gradual decrease in the amount of $\mathrm{FeOH}$ occurs as a result of the dehydration of the $\mathrm{FeOH}$ groups, which leads to an increase in the amount of $\mathrm{O}^{2-}$ groups. This creates a negative surface charge, and $\mathrm{FeOH}$ having an $\mathrm{O}$ atom with increased electron density remains and acts more strongly on $\mathrm{C}_{2} \mathrm{H}_{5} \mathrm{OH}$ as an acid. These chemical changes reduce the electron emission intensity. This produces the convex swelling peak observed in the PE glow curves (Fig. 13). It remains unclear whether this model can be related to the formation of electron trapping sites in the overlayer, as assumed above.

Furthermore, it should be noted that the glow curves of the Up2 scan exhibited a nearly monotonic increase in emission with increasing temperature, although that for benzene was almost the same as the Up1 scan [7]. It remains unclear why the swelling peak is present even in the Up2 scan in the case of benzene.

\subsection{Effect of oxide components and activation energy on PE in the Up2 scan}

Figure 15 shows the relationship between the total count of electrons emitted during the Up2 scan and the intensities of the $\mathrm{FeO}$ and $\mathrm{Fe}_{2} \mathrm{O}_{3}$ components at $339{ }^{\circ} \mathrm{C}$, for the different environments. Interestingly, as shown in Fig. 15(a), the total count of emitted electrons decreased nearly linearly with increasing $\mathrm{FeO}$ intensity, for all environments except benzene. In contrast, as shown in Fig. 15(b), the total count of emitted electrons tended to increase with increasing $\mathrm{Fe}_{2} \mathrm{O}_{3}$ intensity, for all environments except acetone. 

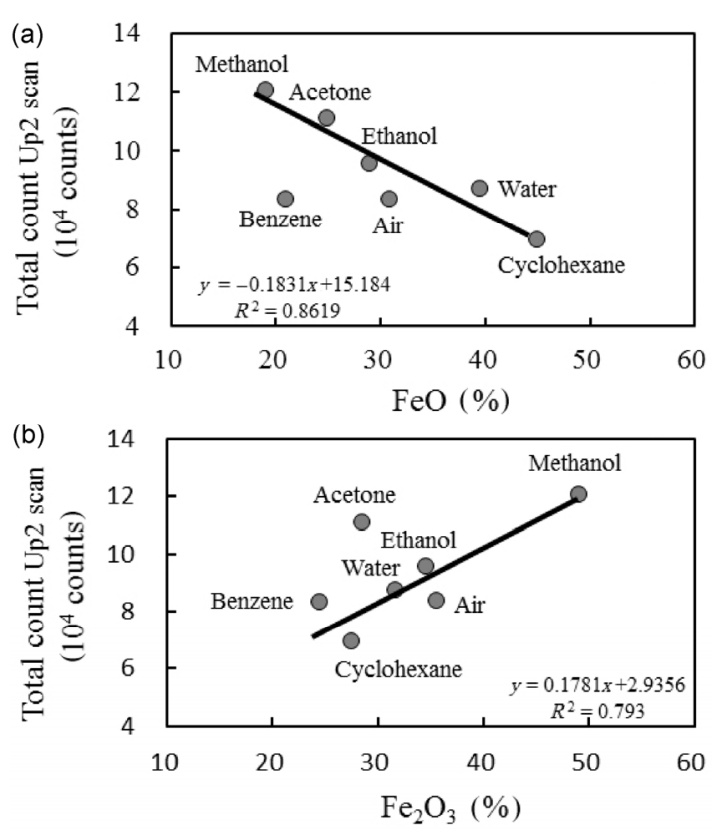

Fig. 15 Plots of the total count of electrons emitted during the Up2 scan, vs. the intensities of the (a) $\mathrm{FeO}$ and (b) $\mathrm{Fe}_{2} \mathrm{O}_{3}$ components at $339^{\circ} \mathrm{C}$, for the different environments. The approximate straight lines given by the equation and $R^{2}$ are shown except for those of benzene in the top figure and acetone in the bottom figure.

In Fig. 7(b) in Ref. [7], we reported that the total count of electrons emitted in the second cycle (i.e., Up2 and Down2 scans) tended to decrease with increasing $\mathrm{O} 1 \mathrm{~s} / \mathrm{Fe} 3 \mathrm{p}$ ratio at $339^{\circ} \mathrm{C}$, for all environments except cyclohexane. Here, we would like to correct the subscript in the "Total count" label given in that figure. That is, "Total count ${ }_{\text {Up2" }}$ should be replaced by "Total

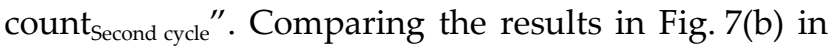
Ref. [7] with the effect of $\mathrm{FeO}$ on the total count of emitted electrons (Fig. 15(a)), it is presumed that the former results may have originated from the effect of the $\mathrm{FeO}$ component at $339^{\circ} \mathrm{C}$, although the order of environments for increasing $\mathrm{O} 1 \mathrm{~s} / \mathrm{Fe} 3 \mathrm{p}$ did not completely agree with that for increasing $\mathrm{FeO}$.

Next, we ask why the increase in the FeO component reduces the total count of emitted electrons. With respect to the electrical conductivity of metal oxides, according to Conder [15], $\mathrm{FeO}$ is a semiconductor and its conductivity increases with temperature from $5 \times 10^{3} \mathrm{~S} \cdot \mathrm{m}^{-1}(330 \mathrm{~K})$ to $10^{4} \mathrm{~S} \cdot \mathrm{m}^{-1}(500 \mathrm{~K})$. Meanwhile, the conductivity of $\mathrm{Fe}_{2} \mathrm{O}_{3}$ is very low, but increases significantly with temperature, from $10^{-16} \mathrm{~S} \cdot \mathrm{m}^{-1}$ (330 K) to $10^{-6} \mathrm{~S} \cdot \mathrm{m}^{-1}(500 \mathrm{~K})$. Therefore, an increase in the amount of $\mathrm{FeO}$ in the overlayer is expected to increase its electrical conductivity, leading to an increased total count of emitted electrons. However, this explanation does not agree with the present experimental results. Roosendaal et al. [16] reported that pre-annealing at $200{ }^{\circ} \mathrm{C}$ under vacuum caused the rate of oxygen incorporation during the room temperature oxidation of $\mathrm{Fe}(100)$ to increase by a factor of $\sim 500$. This was explained as follows: during annealing at $200{ }^{\circ} \mathrm{C}$, electrons and cations are transported to the surface of the sample; the $\mathrm{Fe}^{3+}$ ions present near the surface are reduced to $\mathrm{Fe}^{2+}$. In addition, Xue et al. [17] reported that $\mathrm{Fe}_{2} \mathrm{O}_{3}$ can be transformed to $\mathrm{Fe}_{3} \mathrm{O}_{4}$ after annealing at $800 \mathrm{~K}$ without ambient oxygen. Therefore, regarding the electronic properties of the surface overlayer after the Up1 scan to $339^{\circ} \mathrm{C}$, the outermost region contained accumulated electrons, which did not lead to emission. This negatively charged region acted to suppress the transport of electrons excited from the metal to the outermost surface. Judging from the decrease in the total count of emitted electrons with increasing FeO intensity (Fig. 15(a)), this electron accumulation seemed to increase with increasing $\mathrm{FeO}$ intensity.

We next consider the values of $\Delta E_{\mathrm{aUp} 2}$ obtained in the Up2 scan (Table 2). Except for benzene, the $\Delta E_{\mathrm{aUp} 2}$ values for the different environments satisfied the following: methanol $\left(\Delta E_{\mathrm{aUp} 2}=0.020 \mathrm{eV}\right)<$ acetone $(0.021 \mathrm{eV})<$ ethanol $(0.026 \mathrm{eV})<\operatorname{air}(0.028 \mathrm{eV})<$ cyclohexane $(0.033 \mathrm{eV})<$ water $(0.038 \mathrm{eV})$. Interestingly, this order was almost the same as that of the reduction in the total count of electrons emitted in the Up2 scan and that of the increase in the $\mathrm{FeO}$ intensity, as shown in Fig. 15(a). Therefore, these findings indicate that the total count of electrons emitted in the Up2 scan was closely related to both $\Delta E_{\mathrm{aUp} 2}$ and FeO intensity, for all environments except benzene. It is surprising that the $\mathrm{FeO}$ component, which is adjacent to the metal itself, can contribute to the increase in the PE activation energy. Here, we emphasize that not only the $\mathrm{FeO}$ intensity but also the electronic properties such as electron accumulation presumed for the $\mathrm{FeO}$ become important factors that retard the $\mathrm{PE}$, although the detailed mechanism remains unclear. On the other hand, in Fig. 15(b), an increased $\mathrm{Fe}_{2} \mathrm{O}_{3}$ intensity seemed to increase the total count of electrons emitted in the Up2 scan. This behavior may be related to the reduction 
in $\Delta E_{\mathrm{aUp} 2}$. In this case it seems that the action of $\mathrm{Fe}^{2+}$ ions in $\mathrm{Fe}_{3} \mathrm{O}_{4}$, which is considered to be formed from $\mathrm{Fe}_{2} \mathrm{O}_{3}$ at the outer surface at $339{ }^{\circ} \mathrm{C}$, contributed to the reduction in $\Delta E_{\mathrm{aUp} 2}$ for all environments except acetone. Finally, regarding the deviations of the benzene and acetone data from the straight line in Figs. 15(a) and 15(b), respectively, the following should be noted: In Fig. 9(d), the $\mathrm{FeOOH}$ intensities for benzene and acetone at $339{ }^{\circ} \mathrm{C}$ are considerably higher than those for the other environments (benzene $42.5 \%$, acetone $42.4 \%$ ). Therefore, the increase in the $\mathrm{FeOOH}$ intensity led to the lowering of the $\mathrm{FeO}$ and $\mathrm{Fe}_{2} \mathrm{O}_{3}$ intensities. In addition, in our previous paper [7] we reported that for benzene and acetone the electron emission intensity measured at $200{ }^{\circ} \mathrm{C}$ and $339^{\circ} \mathrm{C}$ in the Up1 scan was almost the same, in spite of the increase in the $\mathrm{FeOOH}$ intensity from $200{ }^{\circ} \mathrm{C}$ to $339^{\circ} \mathrm{C}$. The $\mathrm{FeOOH}$ intensity at $339^{\circ} \mathrm{C}$ seemed to have little effect on the emission.

In the future, based on the PE results obtained from wavelength scans from $300 \mathrm{~nm}$ to $200 \mathrm{~nm}$ in the same way as in a previous paper [6], we will report the temperature dependence of the electron photoemission probability, $\alpha A$, where $A$ is identical to the Richardson constant, and of the photothreshold, $\phi$, and their relationship with the activation energies obtained from the Up1 scans described above.

\section{Conclusions}

We have reported the effect of surface interactions on photoelectron emission (PE) as a function of temperature for real iron surfaces scratched in air, water, and organic environments. The use of several environments and repeated temperature scans revealed a new aspect of the PE activation energy and its relationship to the surface chemical structure analyzed by XPS. The PE was measured using a non-vacuumbased analysis method. First, we demonstrated how the Arrhenius activation energy may be obtained from one PE quantum yield glow curve using samples cleaned only in acetone. Next, PE quantum glow curves were measured for scratched samples for temperatures in the $25-339{ }^{\circ} \mathrm{C}$ range, during two cycles of temperature increase and decrease (Up1, Down1, Up2, and Down2 scans), and a simple method of obtaining the activation energies was introduced and used. The activation energy obtained from the Up1 scan was strongly environment-dependent, while those obtained from the other scans were low and almost the same. The total count of electrons emitted during the Up1 scan decreased with increasing activation energy. In addition, the activation energy obtained from the Up1 scan was explained in terms of the orientation of electric dipoles formed by the acid-base interaction between the molecules of the liquid environment and the surface hydroxyl groups. The total count of electrons emitted in the Up2 scan decreased with increasing activation energy and the increasing intensity of the $\mathrm{FeO}$ component of the $\mathrm{Fe} 3 \mathrm{p}$ spectrum at $339^{\circ} \mathrm{C}$. Furthermore, the convex swelling peak in the PE glow curves in the Up1 scan was explained in terms of the thermal removal of carbon materials weakly bound to the sample surface and the change in the basicity of the $\mathrm{FeOH}$ group under light irradiation.

\section{Acknowledgements}

The authors would like to thank the Ministry of Education, Culture, Sports, Science and Technology of Japan for supporting this work through a grant in aid.

Open Access: The articles published in this journal are distributed under the terms of the Creative Commons Attribution 4.0 International License (http:// creativecommons.org/licenses/by/4.0/), which permits unrestricted use, distribution, and reproduction in any medium, provided you give appropriate credit to the original author(s) and the source, provide a link to the Creative Commons license, and indicate if changes were made.

\section{References}

[1] Spicer W E. Surface analysis by means of photoemission and other photon-stimulated processes. In Chemistry and Physics of Solid Surfaces. Vanselow R, Tong S Y, Ed. Cleveland: CRC Press, 1977: 235-254.

[2] Fowler R H. The analysis of photoelectric sensitivity curves for clean metals at various temperatures. Phys Rev 38: 45-56 (1931)

[3] DuBridge L A. A further experimental test of Fowler's theory of photoelectric emission. Phys Rev 39: 108-118 (1932)

[4] DuBridge L A. New Theories of the Photoelectric Effect. Paris: Hermann and Cie, 1935. 
[5] Momose Y, Suzuki D, Sakurai T, Nakayama K. Influence of temperature and photon energy on quantum yield of photoemission from real iron surfaces. Appl Phys A 117: 1525-1534 (2014)

[6] Momose Y, Suzuki D, Sakurai T, Nakayama K. Photoemission from real iron surfaces and its relationship to light penetration of the overlayer. Appl Phys A 118: 637-647 (2015)

[7] Momose Y, Tsuruya K, Sakurai T, Nakayama K. Photoelectron emission and XPS studies of real iron surfaces subjected to scratching in air, water, and organic liquids. Sur Interface Anal 48: 202-211 (2016)

[8] Hesse R, Chasse T, Szargan R. Peak shape analysis of core level photoelectron spectra using UNIFIT for WINDOWS. Fresenius J Anal Chem 365: 48-54 (1999)

[9] Gutmann V. Ion pairing and outer sphere effect. Chimia 31: 1-7 (1977)

[10] http://en.wikipedia.org/wiki/Proton affinity (data page), Source: Jolly W L. Modern Inorganic Chemistry, 2nd Ed. New York: McGraw-Hill, 1991, [Accessed 12 June 2015].

[11] Bolger J C, Michaels A S. Molecular structure and electrostatic interactions at polymer-solid interfaces. In Interface Conversion for Polymer Coatings. Weiss P, Cheever

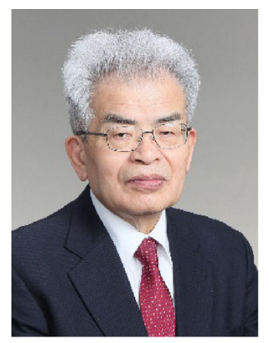

Yoshihiro MOMOSE. He is a professor emeritus of Ibaraki University, Japan. He received his bachelor and master degrees in chemistry in 1963 and 1965, respectively, from Tohoku University, Japan. He joined the faculty of Chemical Research Institute of Non-aqueous Solutions, Tohoku University. He

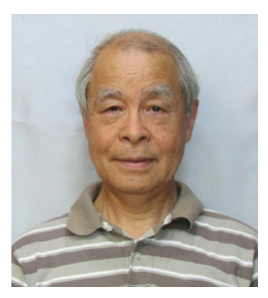

Takao SAKURAI. He received his M.S. and PhD degrees in applied physics from Tokyo Institute of Technology, Japan, in 1969 and 1973,

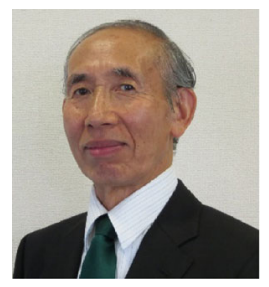

Keiji NAKAYAMA. He is the president of the Institute of Mesotechnology, Japan. He received his master and $\mathrm{PhD}$ degrees in chemical engineering from Tokyo Institute of Technology, Japan, in 1971 and 1974, respectively. He joined to the Mechanical Engineering Laboratory (MEL), AIST, MITI, Japan in 1974. After studying in the field of tribology as a
G D, Eds. New York: Elsevier, 1968: 3-60.

[12] Huheey J E. Inorganic Chemistry, Principles of Structure and Reactivity, 3rd ed. Harper \& Row: New York, 1983. Japanese translation by Kodama G, Nakazawa H. Tokyo Kagaku Dojin: Tokyo, 1984, 340-341 (in Japanese).

[13] Momose Y, Ishii T, Namekawa T. Exoelectron emission from aluminum under the influence of applied electric potential and stimulating light, and its dependence on surface-polar organic interaction. J Phys Chem 84: 2906-2913 (1980)

[14] Grosvenor A P, Kobe B A, McIntyre N S. Studies of the oxidation of iron by water vapour using X-ray photoelectron spectroscopy and QUASES. Surf Sci 572: 217-227 (2004)

[15] Conder K. Electronic and ionic conductivity in metal oxides. Paul Scherrer Institute, Switzerland, pp. 1-44, [Accessed 27 May 2015].

[16] Roosendaal S J, Vredenberg A M, Habraken F H P M. Oxidation of iron: the relation between oxidation kinetics and oxide electronic structure. Phys Rev Lett 84: 3366-3369 (2000)

[17] Xue M, Wang S, Wu K, Guo J, Guo Q. Surface structural evolution in iron oxide thin films. Langmuir 27 (1): 11-14 (2011)

earned his PhD degree in 1970 from Tohoku University. After that he worked in the Department of Engineering Chemistry and Materials Science at Ibaraki University as an associate professor and then a professor from 1970 to 2006. His main research interest focuses on the transfer of charge and electrons on the real surfaces in the fields such as tribochemistry, adhesion, and corrosion.

respectively. His current position is an emeritus professor of Ashikaga Institute of Technology. His research interests include curve analyses in the field of thermally stimulated relaxation processes.

researcher, a senior researcher, and the head of division in MEL, he worked as a professor in the Advanced Research Institute, Chiba Institute of Technology, Japan from 2008 to 2014 . He is in the current position since 2014. His main research interest focuses on the basic and application studies of the triboelectromagnetic phenomena, which embrace triboplasma generation, triboemission of charged particles and photons, and tribocharging. 